\title{
Screening Potential Probiotic Characteristics of Lactobacillus brevis Strains In Vitro and Intervention Effect on Type I Diabetes In Vivo
}

\author{
Amro Abdelazez $\mathbb{D}^{1,2}$ Heba Abdelmotaal ${ }^{10},{ }^{3,4}$ Smith Etareri Evivie, \\ Sherif Melak, ${ }^{6,7}$ Fang-Fang Jia, ${ }^{1}$ Mir Hassan Khoso, ${ }^{4}$ Zong-Tao Zhu, ${ }^{1}$ \\ Lu-Ji Zhang, ${ }^{1}$ Rokayya Sami ${ }^{D},{ }^{8}$ and Xiang-Chen Meng ${ }^{1}{ }^{1}$ \\ ${ }^{1}$ Key Laboratory of Dairy Science of Ministry of Education, Northeast Agricultural University, Harbin 150030, China \\ ${ }^{2}$ Department of Dairy Microbiology, Animal Production Research Institute, Agriculture Research Centre, Dokki, Giza 12618, Egypt \\ ${ }^{3}$ Department of Microbiology, Soil, Water, Environment, and Microbiology Research Institute, Agriculture Research Center, \\ Giza 12619, Egypt \\ ${ }^{4}$ Department of Microbiology and Biotechnology, College of Life Sciences, Northeast Agricultural University, Harbin 150030, China \\ ${ }^{5}$ Department of Animal Science, Faculty of Agricultural, University of Benin, 1154, Benin City, Edo State, Nigeria \\ ${ }^{6}$ Department of Animal Science and Biotechnology, College of Animal Science and Technology, \\ Nanjing Agricultural University, Nanjing 210095, China \\ ${ }^{7}$ Department of Sheep and Goat, Animal Production Research Institute, Agriculture Research Centre, Dokki, Giza 12618, Egypt \\ ${ }^{8}$ Department of Food Science and Nutrition, Taif University, Taif, Al-huwayah 888, Saudi Arabia
}

Correspondence should be addressed to Xiang-Chen Meng; xchmeng@hotmail.com

Received 22 May 2018; Revised 21 July 2018; Accepted 8 August 2018; Published 19 September 2018

Academic Editor: Kota V. Ramana

Copyright (C) 2018 Amro Abdelazez et al. This is an open access article distributed under the Creative Commons Attribution License, which permits unrestricted use, distribution, and reproduction in any medium, provided the original work is properly cited.

\begin{abstract}
Diabetes has become the third most serious threat to human health, after cancer and cardiovascular disease. Notably, Lactobacillus brevis is the most common species of LAB that produces $\gamma$-aminobutyric acid (GABA). The aim of this study is to clarify the effect of time, strain types, antibiotic concentrations, different levels of $\mathrm{pH}$, and intestinal juices in aerobic or anaerobic conditions and the effect of interactions between these factors on the potential properties of KLDS 1.0727 and KLDS 1.0373, furthermore, antagonistic activity against foodborne pathogens. Moreover, another aim is to study the capability of KLDS 1.0727 and KLDS 1.0373 strains as gad gene carriers to express GABA that reduce the risk of type 1 diabetes in C57BL/6 mice as diabetic models. The obtained results exhibited the surprising tolerance of Lactobacillus brevis strains in vitro digestion models mimicking the conditions of the gastrointestinal tract, further, large antagonistic activity against foodborne pathogeneses. In vivo results displayed the significant effect on glucose level reduction, blood plasma, and histological assays of mice organs. As recommended, the use of Lactobacillus brevis strains should be widely shared in the market as a natural source of GABA in pharmaceutical and food applications.
\end{abstract}

\section{Introduction}

Nowadays, food plays a vital role in inhibiting diseases and ensuring health. One of the most important challenges facing customers is the safety of high-quality healthy foods and the creation of a new diet that focuses on the prevention of chronic diseases and disorders [1]. Functional food acts as beneficial compounds or foods containing microorganisms exhibiting a pivotal role in strengthening and enriching health well-being and suppressing some strict disease, for instance, obesity, diabetes, atherosclerosis, heart disease, retinopathy, kidney toxicity, atherosclerosis, hypertension, diabetic foot ulcers, and cystic fibrosis [2,3]. The most vital components of new functional foods are called probiotics, 
which can increase host immunity and improve health benefits [4]. Recently, various conventional microorganisms have been used for probiotic cultures in fermented foods. Furthermore, probiotics include a wide range of pharmaceuticals or foods and special dietary applications such as juices, nutrition bars, infant formulas, and cosmetics [5].

The medical application of Lactobacillus brevis KB 290, isolated from "Suguki", is a traditional Japanese pickle that plays a crucial role against people with influenza [6]. In addition, it plays a vital role in suppressing inflammation caused by nitric oxide [7]. Several studies have been conducted on several Lactobacillus brevis strains isolated from traditional Egyptian dairy products, which have been tested to confirm their antimicrobial effects. These results show the extreme activity of Lactobacillus brevis B23 among 38 species [8]. Lactobacillus brevis is a vital biological organism to produce bioactive $\gamma$-aminobutyric acid biologically [9]. Formerly, $\gamma$ aminobutyric acid (GABA) has been attracting attention because it is the most abundant inhibitory neurotransmitter that maintains the neurotransmitter functions of the human central nervous system. Furthermore, GABA may not have the ability to penetrate the human blood-brain barrier [10]. gad antibodies, a symptom of type 1 diabetes, can be detected before the onset of clinical disease and the identification of a subset of patients with adult autoimmune disease [11].

Currently, more than a thousand LAB strains have been sequenced and deposited in the NCBI GenBank database. Therefore, genetic assays were performed in most continuous strains in the presence or absence of gad operon and genes encoding glutamate decarboxylase in most of the sequenced strains. Moreover, there are not only differences between microbial species from different sources in the gad enzymatic properties but also differences between the subspecies as well. Lactobacillus different sources of gad subunit composition and molecular weight have a huge difference. Lactobacillus brevis gad has two subunits molecular weight of $57,60 \mathrm{kDa}$ [12].

$\gamma$-Aminobutyric acid (GABA) is a nonprotein, fourcarbon, free amino acid, synthesized by the irreversible $\alpha$-decarboxylation reaction of L-glutamic acid or its salts, a pyridoxal-50-phosphate-dependent enzyme (PLP; active vitamin B6)[13]. GABA is permitted as a dietary ingredient and its nutrients have shown antihypertensive and antidepressant activities as the two main functions of the host after oral administration [9]. However, the GABA content in a few natural plants and animal products has been further studied in the LABs because it also possesses the ability to produce GABA.

Type 1 diabetes (T1D) is an autoimmune disease characterized by selective destruction of the pancreatic beta cells [14]. Furthermore, it is a metabolic disease induced by abnormal insulin secretion by damaged islet $\beta$ cells. That damage accrues resulting in insulin insufficiency, which can lead to life-threatening hyperglycemia that manifests clinically as weight loss, polyuria, polyphagia, and polydipsia [15]. LAB could be utilized to grab foodborne diseases, researchers used Salmonella typhimurium, which causes vomiting, abdominal pain, nausea, and diarrhea [16], Listeria monocytogenes, which causes abortion and gastrointestinal diseases [17], Staphylococcus comets, which is involved in harmful gastroenteritis, and E. coli, thereby exacerbating the syndrome and colitis [18].

The main objective of the present study was to examine the new Lactobacillus brevis probiotic strains that could efficiently produce high levels of bioactive $\gamma$-Aminobutyric Acid (GABA) by exploring gad gene, in addition, study potential probiotic properties in vitro where they remain in severe case of simulation gastrointestinal juice and different types of antibiotics and, moreover, antimicrobial activity against foodborne pathogens, and finally, control the development of type 1 diabetes in vivo.

\section{Materials and Methods}

2.1. Bacterial Strains and Cultivation Conditions. Two strains of Lactobacillus brevis KLDS 1.0727 and KLDS 1.0373 were frozen stored at $-80^{\circ} \mathrm{C}$. Further, the foodborne pathogenic microorganisms used were Salmonella typhimurium (ATCC ${ }^{\circledR}$ 14028-MINI-PACK ${ }^{\mathrm{TM}}$ ) (American Type Culture Collection), E. coli IQCC 10126, Listeria monocytogenes IQCC 22221, and Staphylococcus aureus IQCC 22035 (Inspection and Quarantine Culture Collection of the Chinese Academy of Inspection and Quarantine culture libraries, IQCC). All test strains were obtained from Key Laboratory of Dairy Science (KLDS), Heilongjiang Province Harbin, China.

Lactobacillus brevis KLDS 1.0727 and KLDS 1.0373 strains were inoculated $(1 \% \mathrm{v} / \mathrm{v})$ and grown in De Man Rogosa Sharpe medium (MRS Oxoid), while foodborne pathogenic bacteria were grown in Tryptic Soy Broth (TSB) (Sigma Aldrich). All the strains were cultivated at $37^{\circ} \mathrm{C}$ aerobically for 24 hours. The solid plates medium was cultivated for 48 hours, single colonies were picked, after examination of the pure bacteria, and they were then cultivated in an adequate liquid culture medium.

KLDS 1.0727 and KLDS 1.03737 colonies were streaked on MRS agar plate and incubated at $37^{\circ} \mathrm{C}$ for 24 hours under aerobic conditions. Colonies were randomly picked from the plates and subculture two or three times on fresh MRS agar plates. A single colony from the plate was transferred to MRS broth and incubated for 18 hours at $37^{\circ} \mathrm{C}$. The pure KLDS 1.0727 and KLDS 1.0373 cultures were kept in MRS broth supplemented with $30 \%(\mathrm{v} / \mathrm{v})$ glycerol and frozen at $-80^{\circ} \mathrm{C}$ until further analysis.

\subsection{Screening of Lactobacillus brevis KLDS 1.0727 and KLDS 1.0373 Strains for the Presence of Glutamic Acid Decarboxylase (gad) Gene. Genomic DNA was prepared using TIANamp Bacterial DNA Kit (Tiangen Biotech Co., Ltd, Beijing, China) and with some modification of manufacturer's extraction steps KLDS 1.0727 and KLDS 1.0373 were lysed with lysozyme DNA extracted.}

2.3. PCR Amplification of the $16 S$ rDNA and Sequence Anal$y$ sis. PCR amplification was performed using the universal primers: 


$\begin{array}{lc}\text { Primer ID } & \text { Sequences }\left(5^{\prime} \longrightarrow 3^{\prime}\right. \\ \text { Lb-PTC-F } & \text { GCCAGAAACGCTCAAGAT } \\ \text { Lb-PTC-R } & \text { GGCTTCGTATAAGCCATACC } \\ \text { Lb-OTC-F } & \text { GTGAAAGCAACTGGGAAGA } \\ \text { Lb-OTC-R } & \text { GTTATGGAAAGCAGGCAAAC } \\ \text { Lb-TDC-F } & \text { CGATCAAGCAGAGTCCATTAC } \\ \text { Lb-TDC-R } & \text { CGGCACCCTTCTCAAATAC }\end{array}$

Genomic DNA was used as a template for PCR amplification. Fifty microliters of each PCR mixture contained DNA template $1.0 \mu \mathrm{L}$, two primer pairs (ComateBio Custom Primers, Jilin, Changchun, China), gad-F/gadR (10 $\mu \mathrm{mol}$ / L) $2.0 \mu \mathrm{L}$, [19] DNA Polymerase $(2.5 \mathrm{U} / \mu \mathrm{L}) 0.5 \mu \mathrm{L}$, $10 \times$ Taq Buffer $5.0 \mu \mathrm{L}, 2$ '-deoxynucleoside 5 ' triphosphate (dNTPs) $(2.5 \mathrm{mM}) 4.0 \mu \mathrm{L}$, and $\mathrm{ddH}_{2} \mathrm{O} 35.5 \mu \mathrm{L}$. Furthermore, PCR amplification was performed using the GeneAmp PCR System 9700 thermal cycler (Applied Biosystem, USA) with the thermal cycling parameters as follows: denaturation at $95^{\circ} \mathrm{C}$ for $5 \mathrm{~min}, 30$ cycles of $95^{\circ} \mathrm{C}$ for $30 \mathrm{~s}, 55^{\circ} \mathrm{C}$ for $1.30 \mathrm{~min}$ and $72^{\circ} \mathrm{C}$ for $1.30 \mathrm{~min}$, with a final extension at $72^{\circ} \mathrm{C}$ for 10 min. A $5-\mu \mathrm{L}$ volume of PCR product was electrophoresed on a $1 \%$ agarose gel (Gibco BRL, France) at $90 \mathrm{~V}$ for 1.5 hours and then stained with ethidium bromide and band patterns were visualized. Sequence similarity analysis was performed in the GenBank database using the BLAST program (http://blast.ncbi.nlm.nih.gov/Blast.cgi) (NCBI).

2.4. Evaluation of KLDS 1.0727 and KIDS 1.0373 In Vitro Digestion Models Mimicking the Gastrointestinal Tract. In vitro assessment has been tested for the viability of KLDS 1.0727 and KLDS 1.0373, for example, growth rate, bile salts, simulated intestinal juice (SIJ) at different $\mathrm{pH}$ levels under aerobic or anaerobic conditions [20], and surviving in a wide range of different antibiotics types. The antagonism of various foodborne pathogens and, furthermore, all experiments were expressed in triplicate using the MRS broth as a blank. In addition, the absorbance was measured with a wavelength of $620 \mathrm{~nm}$ and the data were expressed as OD.

2.4.1. Standard Curve of Growth Rate and pH for KLDS 1.0727 and KLDS 1.0373 strains. KLDS 1.0727 and KLDS 1.0373 strains were inoculated $(1 \% \mathrm{v} / \mathrm{v})$ and grown in MRS broth at $37^{\circ} \mathrm{C}$ under aerobic conditions. The growth bacteria were monitored using a spectrophotometer (F-7000, Hitachi High Technologies, 155 Shenzhen, China), and $\mathrm{pH}$ was determined by using $\mathrm{pH}$ meter (MP 220, Mettler Toledo, Greifensee, Switzerland).

2.4.2. Resistance of KLDS 1.0727 and KLDS 1.0373 to Different Bile Salts Concentration in MRS Incubated at $37^{\circ} \mathrm{C}$. KLDS 1.0727 and KLDS 1.0373 were tested for hydrolyzed bile salt activity. The strains were cultured in MRS broth added to $0.3,1$, and $2 \%(\mathrm{w} / \mathrm{v})$ of the bovine bile (Difco, DB Diagnostic System, reference 212820) and incubated at $37^{\circ} \mathrm{C}$ under aerobic conditions, then the tested media were obtained as a filtration solution through a $0.22 \mu \mathrm{m}$ filter (Critical Syringe Filters; Critical Process Filtration Inc). The activated strains in the MRS broth were taken without Ox gall powder as a
Reference control [21]. The following equation expressed the survival percentage of bile salts after 33 hours.

$$
\text { Bile survival } \%=\frac{\log \mathrm{N} 1}{\log \mathrm{N} 0} \times 100
$$

$\mathrm{N} 1$ is absorbance of cultures in MRS broth containing $0.3,1$, and $2 \%$ bile salts (see [22]). $\log \mathrm{N} 0$ is absorbance of cultures in MRS broth without bile salts.

\subsubsection{Resistance of KLDS 1.0727 and KLDS 1.0373 to Different} Types of Antibiotics. The microdilution protocol was used to assess the resistance of probiotic bacteria to different types of antibiotics [23] with some modifications according to EFSA Guidance [24]. The antibiotics ampicillin, chloramphenicol, erythromycin, gentamycin, kanamycin (Sigma Aldrich, St. Louis, MO), and streptomycin (MP Biomedicals, Santa Ana, $\mathrm{CA}$ ) and the amounts of the active compound were placed into the broth media tube: ampicillin $(10 \mu \mathrm{g})$, chloramphenicol $(30 \mu \mathrm{g})$, erythromycin $(15 \mu \mathrm{g})$, gentamycin $(10 \mu \mathrm{g})$, kanamycin $(30 \mu \mathrm{g})$, and streptomycin $(10 \mu \mathrm{g})$. Cultures were inoculated in MRS broth filtered through a $0.22-\mu \mathrm{m}$ filter and incubating aerobically at $37^{\circ} \mathrm{C}$ overnight. Furthermore, antibiotic stock solutions were prepared according to the following formula:

$$
\mathrm{W}=\frac{1000}{\mathrm{P}} \times \mathrm{V} \times \mathrm{C}
$$

where $\mathrm{P}$ is potency given by the manufacturer $(\mu \mathrm{g} / \mathrm{mg}), \mathrm{V}$ is volume required $(\mathrm{ml}), \mathrm{C}$ is final concentration of solution (multiples of 1000, $\mathrm{mg} / \mathrm{L}$ ), and $\mathrm{W}$ is weight of antibiotic $(\mathrm{mg}$ ) to be dissolved in volume $\mathrm{V}(\mathrm{mL})$. The data was expressed after 24 hours as the following formula:

$$
\begin{aligned}
\text { Survival } \% & =\frac{\log \mathrm{N} 1}{\log \mathrm{N} 0} \times 100 \\
\text { Sensitivity of antibiotic } & =100-\text { survival } \%
\end{aligned}
$$

$\log \mathrm{N} 1$ is absorbance of culture $620 \mathrm{~nm}$ in MRS broth with different antibiotic types and $\log \mathrm{N} 0$ is absorbance of culture $620 \mathrm{~nm}$ in MRS broth as a control.

2.4.4. Tolerance of KLDS 1.0727 and KLDS 1.0373 to Simulated Intestinal Juice (SIJ) with Different $p H$ under Aerobic or Anaerobic Conditions. Lactobacillus brevis strains are a facultative anaerobic LAB strains. Therefore, KLDS 1.0727 and KLDS 1.0373 strains were propagated in Lactobacilli MRS broth for 24 hours. Simulated intestinal juice (SIJ) (grams/100 $\mathrm{ml}$ ) was prepared as follows: 0.1 of trypsin; 1.8 of bile salts; 
1.1 of sodium bicarbonate; 0.2 of sodium chloride followed by adjusting the final $\mathrm{pH}$ to $2.0,3.0$, and 7.0 and sterilizing the obtained solution by filtration through $0.22 \mu \mathrm{m}$ filter [25]. Afterwards, an appropriate amount $\left(10^{9} \mathrm{CFU} / \mathrm{mL}^{-1}\right)$ of the freshly prepared inoculum of KLDS 1.0727 and KLDS 1.0373 strains was inoculated into the prepared (SIJ) and incubated for $0,3,6$, and 24 hours. Moreover, anaerobic conditions designed by anaerobic glove chamber (Sheldon Manufacturing, Inc., Shel LAB, Cornelius, OR, USA) were used with a gas mixture of $\left(90 \% \mathrm{~N}_{2}, 5 \% \mathrm{CO}_{2}, 5 \% \mathrm{H}_{2}\right)$. According to the comparison of these strains in the ability to survive after 24 hours,

$$
\text { Survival } \%=\frac{\log \mathrm{N} 1}{\log \mathrm{N} 0} \times 100
$$

where $\log \mathrm{N} 1$ is absorbance of culture $620 \mathrm{~nm}$ in MRS broth at $\mathrm{pH} 2,3$, and 7 and $\log \mathrm{N} 0$ is absorbance of culture $620 \mathrm{~nm}$ in MRS broth as a control.

2.4.5. Screening Antagonistic Properties of KLDS 1.0727 and KLDS 1.0373 Strains. Antagonistic activities were assessed by measuring clear zones $\mathrm{mm}$ from the edge as described by Damaceno et al. [26]. Two single strains of KLDS 1.0727 and KLDS 1.0373 and foodborne pathogens Salmonella typhimurium ATCC 14028, E. coli IQCC 10126, Listeria monocytogenes IQCC 22221, and Staphylococcus aureus IQCC 22030 as indicator strains studied for antagonism were used. Agar slabs of 6-mm in diameter were aseptically cut off from the MRS agar overgrown with a lawn of KLDS 1.0727 and KLDS 1.0373 strains incubated for 24 hours at $37^{\circ} \mathrm{C}$, under aerobic conditions and placed on plates with the Tryptic Soy Medium agar inoculated with the indicator strain $\left(10^{5}-10^{6}\right.$ $\mathrm{CFU} / \mathrm{mL}$ ). The plates were kept at $4^{\circ} \mathrm{C}$ for 3 hours to permit diffusion on the assay material and incubated at $37^{\circ} \mathrm{C}$ for 24 hours of incubation and then the diameters of clear zones around the agar slabs were measured. To compare the antagonistic activity of KLDS 1.0727 and KLDS 1.0373 strains against the indicator cultures, the clear zones were expressed as $14 \mathrm{~mm}, 3$ points; $9-14 \mathrm{~mm}, 2$ points; $1-8.9 \mathrm{~mm}, 1$ point.

2.5. Caco-2 Cell Adhesion Assay. The ability of KLDS 1.0727 and KLDS 1.0373 strains was tested for adherence to human epithelial cells using Caco-2 cells (human colonic adenocarcinoma, ATTC HTB-37) [27]. Monolayers of Caco-2 cell line obtained from China Cell Bank, Shanghai, were grown in Dulbecco's modified Eagle's Medium (Sigma, Aldrich) high glucose supplemented with $10 \%(\mathrm{v} / \mathrm{v})$ fetal bovine serum (Gibco, reference 12484-028), 1\% (v/v) nonessential amino acid, and $1 \%(\mathrm{v} / \mathrm{v})$ penicillin-streptomycin at $37^{\circ} \mathrm{C}$ in a humidified atmosphere of $95 \%$ air and $5 \% \mathrm{CO}_{2}$. The Caco-2 cell concentration was adjusted to $5 \times 10^{5}$ cell $/ \mathrm{mL}$ and seeded into well tissue culture plates and, subsequently, incubated at $37^{\circ} \mathrm{C}$ in a $5 \% \mathrm{CO}_{2}$ incubator until the Caco- 2 cells attained a confluent differentiated monolayer state $(15 \pm 1 \mathrm{~d})$. The Caco2 monolayer was washed twice with sterile PBS to eliminate the penicillin-streptomycin. The KLDS 1.0727 and KLDS 1.0373 strains were harvested by centrifugation $(10,000 \mathrm{~g}, 5$ $\min , 4^{\circ} \mathrm{C}$ ) and washed twice with sterile PBS. Then, density was adjusted with high-glucose DMEM without antibiotics to $10^{8} \mathrm{CFU} / \mathrm{mL}$. Afterwards, $1 \mathrm{~mL}$ of each KLDS 1.0727 and KLDS 1.0373 strains suspension were added to the wells, and the plates were incubated for 2 hours at $37^{\circ} \mathrm{C}$ in a $5 \% \mathrm{CO}_{2}$ atmosphere. At the end of the assay, Caco- 2 cells were washed three times with sterile PBS to remove unadhered KLDS 1.0727 and KLDS 1.0373 cells.

The Caco-2 monolayers were lysed by treatment with EDTA-trypsin solution for $3-5 \mathrm{~min}$ at $37^{\circ} \mathrm{C}$ for disrupting the adherent cells. The Caco- 2 lysate and the attached KLDS 1.0727 and KLDS 1.0373 cells were plated on MRS agar plate after serial dilution and counted after 24 hours of incubation at $37^{\circ} \mathrm{C}$. The adhesion ability of KLDS 1.0727 and KLDS 1.0373 was determined using the following formula:

$$
\text { Adhesion } \%=\frac{\log \mathrm{Nt}}{\log \mathrm{N} 0} \times 100
$$

where $\log \mathrm{Nt}$ is the number of KLDS 1.0727 and KLDS 1.0373 strains that adhered to the Caco-2 monolayers, and log N0 is a total number of KLDS 1.0727 and KLDS 1.0373 strains added as a control blank.

Moreover, the direct microscopic examination method was used to disable the adhesion of KLDS 1.0727 and KLDS 1.0373 with Caco2 cells after $(15 \pm 1 \mathrm{~d})$ of cultivation as described above. The culture medium was replaced with an antibiotic-free medium one day prior to the adhesion assay. Afterwards, the cells were washed twice with phosphatebuffered saline (PBS) $(\mathrm{pH}=7.2)$; KLDS 1.0727 and KLDS 1.0373 strains were added to the prepared cell monolayers. After 2 hours of incubation at $37^{\circ} \mathrm{C}$, all monolayers were washed 5 times with PBS to remove nonadherent bacteria. Finally, binding between Lactobacillus brevis strains and Caco 2 cells was examined by Gram-stained phase contrast microscopy (magnification fold, $200 \mathrm{x}$ ). The adhered Lactobacillus brevis strains Caco 2 cells were determined in 15 randomly selected microscopic fields.

\subsection{In Vivo Experiments}

2.6.1. Animal Experiments Design and Establishment of Diabetic Model Mice. Specific pathogen-free (SPF) male mice C57BL/6 (6-8 weeks old) were purchased from Vital River Laboratory Animal Technology Co., Ltd. (Beijing, China), housed in a room under controlled environmental conditions at $23 \pm 2^{\circ} \mathrm{C}$, a relative humidity of $50 \pm 20 \%$ with artificial light cycle a 12 -h light/dark. Mice were raised in independent, ventilated cages and received pathogen-free food and water. The mice were acclimatized for one week of the laboratory conditions before beginning the experiments. The experimental protocol was approved by the Institutional Animal Care and Use Committee of the Northeast Agricultural University under the approved protocol number specific pathogen-free rodent management (SRM)-06.

Table 1 shows the animal experimental designed; the animals were divided into five groups within four mice per group. Afterwards, the diabetic mice were treated with high dose of streptozotocin (STZ, $180 \mathrm{mg} / \mathrm{kg}$ ) (Sigma, Aldrich) freshly prepared in $50 \mathrm{mM}$ sodium citrate buffer ( $\mathrm{pH} 4.5)$ and subcutaneously injected within 10 to $15 \mathrm{~min}$ after dissolving 
TABLE 1: Experiments design of diabetic model mice.

\begin{tabular}{ccccc}
\hline Group Treatment & & Dose/ mouse & Time of treated & Methods of delivered \\
\hline & $($ Cont $)$ & $250 \mu \mathrm{L}$ Saline & Daily & via gavage \\
& $(\mathrm{STZ})$ & $180 \mathrm{mg} / \mathrm{kg}$ & One time & subcutaneously \\
& $(\mathrm{INS}+\mathrm{STZ})$ & $100 \mu \mathrm{L}$ & Daily & subcutaneously \\
Male C57BL/6 & $(\mathrm{S} 1)$ & $250 \mu \mathrm{L}$ & Daily & via gavage \\
\hline
\end{tabular}

(Cont), control group; (STZ), streptozotocin; (INS+STZ), insulin + streptozotocin; (S1), KLDS1.0727+ streptozotocin, and (S2), KLDS1.0373+ streptozotocin.

for one time according to a previously described procedure [28].

The nondiabetic control group received an injection of citrate buffer only 3 days post-STZ-injection; glucose levels were measured using a glucometer (Yuwell, Jiangsu, China). The mice with glucose levels higher than $\geq 7 \mathrm{mmol} / \mathrm{dl}$ were considered diabetic and STZ-induced mice that had a lower glucose level were excluded.

2.6.2. Weekly Determination of Glucose Level and Body Weight of Streptozotocin-Induced Diabetic Mice. Following blood glucose, blood glucose level and body weight of overnight fasting for 12 hours and 2 hours postprandial were assessed weekly. Glucose levels were measured using a glucometer and glucose expressed as $\mathrm{mmol} / \mathrm{dl}$.

$$
\begin{aligned}
\text { Glucose level }= & \text { Postprandial } 2 \text { hours } \\
& - \text { Fasting } 12 \text { hours }
\end{aligned}
$$

2.6.3. Plasma Biochemical Analyses. After feeding for four weeks, fasting blood samples were collected from the ocular vein of each group and allowed to clot at $4^{\circ} \mathrm{C}$ and then centrifuged at $12,000 \times \mathrm{g}$ for $10 \mathrm{~min}$. The plasma was transferred to a new microcentrifuge tube and stored in a $-80^{\circ} \mathrm{C}$ for biochemical measurements. The blood plasma was determined for serum lipids concentrations as triglyceride (TG); total cholesterol (CHOL); high-density lipoprotein cholesterol (HDL); low-density lipoprotein cholesterol (LDL); glucose (GLU); magnesium $\left(\mathrm{Mg}^{+2}\right)$ which were measured. Furthermore, liver functions were evaluated by assessing serum alanine aminotransferase (ALT), aspartate transaminase (AST); AST/ALT; total bile acid (TBA); albumin (ALB); globulin (GLUB); total protein (TP). Moreover, determination of kidney functions such as uric nitrogen (BUN); creatinine (CREA); uric acid (URIC) levels was assessed as well. All test parameters were a determination by using a Beckman Coulter UniCel DxC 800 (Beckman Coulter, Miami, FL, USA) analyzer.

2.6.4. Serum Insulin Determination. Mice were fed rodent chow for 4 weeks with injected daily with insulin (Sigma) using dose unit ( 0.5 units/ $\mathrm{kg}$ body weight). Insulin was diluted in acetic acid for a final injected volume of $100 \mu \mathrm{l}$. Insulin sensitivity was evaluated essentially as described by Surwit et al., [29]. Blood serum insulin was detected by insulin determination ELISA kits (Meimian Biotech Co., Ltd., Yancheng, China). The experimental process was according to the manufacturer's instructions of insulin kits.

2.6.5. Histological Evaluation. The experimental procedures used for routine histological examination of organs in mice tissue were previously described [30]. Briefly, the mice organs (liver, pancreas, kidney, and spleen) were removed and washed by phosphate buffer ( $\mathrm{pH} 7.2$ ) and then fixed in 10 $\%$ neutral formalin, followed by dehydrating in gradient alcohol $(75 \%, 85 \%, 95 \%$, and $100 \%)$ and xylene (100\%), then embedded in paraffin, and sectioned at $5 \mathrm{~mm}$ thickness, subsequently followed by staining in hematoxylin and eosin after euthanasia tissues staining. The sections were assessed by light microscopy (Olympus, Japan) under $100 \times$ magnifications.

2.7. Statistical Analysis. All values were expressed as the mean \pm standard deviation (SD). A minimum of three independent experiments was carried out for each assay. The statistical significance of data comparisons was determined using oneway analysis of variance (ANOVA). Values of $p<0.05$ were considered statistically significant. Statistical analysis using SAS system software (version 9.1, SAS Institute, Cary, NC, USA) was used to calculate $\mathrm{F}$ values and compare between means by Duncan's multiple range test. Two statistical models were used to estimate phenotypic traits as follows:

$$
\begin{aligned}
\mathrm{Y}_{\mathrm{ijk}}= & \mu+\mathrm{A}_{\mathrm{i}}+\mathrm{B}_{\mathrm{j}}+\mathrm{AB}_{\mathrm{ij}}+\mathrm{e}_{\mathrm{ijk}} \\
\mathrm{Y}_{\mathrm{ijkl}}= & \mu+\mathrm{A}_{\mathrm{i}}+\mathrm{B}_{\mathrm{j}}+\mathrm{C}_{\mathrm{k}}+\mathrm{AB}_{\mathrm{ij}}+\mathrm{AC}_{\mathrm{ik}}+\mathrm{BC}_{\mathrm{jk}} \\
& +\mathrm{ABC}_{\mathrm{ijk}}+\mathrm{e}_{\mathrm{ijk} \mathrm{kl}}
\end{aligned}
$$

where $Y_{i j k}$ is phenotype traits; $\mu$ is the overall mean; $A_{i}$ is the effect of the $i^{\text {th }}$ strains; $B_{j}$ is the effect of the $j^{\text {th }}$ time levels; $\mathrm{C}_{\mathrm{k}}$ is the effect of the $\mathrm{k}^{\text {th }}$ concentrations or antibiotic types. Further, $\mathrm{AB}_{\mathrm{ij}}$ is the interaction between $\mathrm{i}^{\text {th }}$ strains and $\mathrm{j}^{\text {th }}$ time levels. Moreover, $\mathrm{AC}_{\mathrm{ik}}$ is the interaction between strains and $\mathrm{k}^{\text {th }}$ concentrations or antibiotic types, $\mathrm{BC}_{\mathrm{jk}}$ is the interaction between $\mathrm{j}^{\text {th }}$ time and $\mathrm{k}^{\text {th }}$ concentrations or antibiotic types, $A B C_{i j k}$ is the interaction between $i^{\text {th }}$ strains, $j^{\text {th }}$ time levels, and $\mathrm{k}^{\text {th }}$ concentrations or antibiotic types, and $\mathrm{e}_{\mathrm{ijk}}$ is the effect of the random error. 


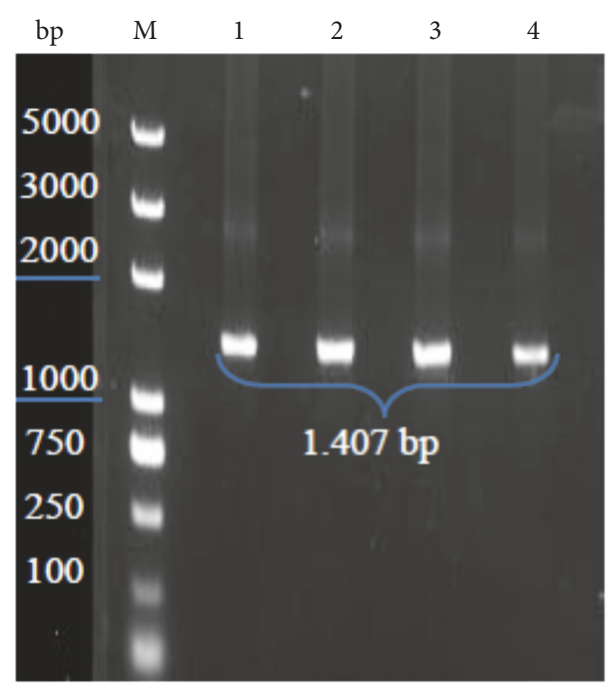

Figure 1: PCR amplification of gad gene. M: marker; 1, 2 PCR products of Lactobacillus brevis KLDS 1.0727 and 3, 4 of KLDS 1.0373 .

\section{Results}

3.1. PCR Amplification of the $16 S$ rDNA and Sequence Analysis. Figure 1 showed the PCR amplification results of the presence gad gene and the nucleotide sequence of gad displayed the 1,407 bp. Further, our previous study reported the HPLC chromatogram analysis for GABA produced by KLDS 1.0727 and KLDS 1.0373 was $1.98 \pm 0.07$ and $0.05 \pm 0.05 \mathrm{~g} / \mathrm{L}$, respectively (data no shown). Several studies have shown that the analysis of the sequence of nucleotide gad showed cloned genes consisting of $1,407 \mathrm{bp}$ and 468 amino acids were encoded [31]. These results were closely related to the findings by Hiraga et al. [32] who suggested that the gad gene of Lactobacillus brevis IFO 12005 was 1,440 bp. Moreover, Wu et al. [19] reported that biochemical analysis and genetic screening have confirmed the common existence of gad system in Lactobacillus brevis suggesting its species-specific characteristic of GABA production.

\subsection{Assessment of Lactobacillus brevis KLDS 1.0727 and KLDS} 1.0373 In Vitro. The in vitro results obtained in three main Tables 2, 3, and 4 will be expressed to show the effect of some factors (strain types, time level, concentrations, and interaction of different parameters) as the equations of the statistics model mentioned above.

\subsection{Determination of the Growth Rate and Bile Tolerance of} Lactobacillus brevis KLDS 1.0727 and KLDS 1.0373 Strains. The obtained results in Figure 2 showed the standard curve of growth rate and bile tolerant with the accumulated acid of KLDS 1.0727 and KLDS 1.0373 strains. There was a significant positive correlation between growth rate and $\mathrm{pH}$ (0.98). Duncan comparisons between strains showed highly significant differences between KLDS 1.0727 and KLDS 1.0373 as shown in Table 2. KLDS 1.0727 showed a high growth rate and decreased $\mathrm{pH}$ values more than KLDS 1.0373 (1.24 \pm 0.19 and $1.15 \pm 0.21$, respectively), where the $\mathrm{pH}$ is shown in Table 3 as follows ( $4.45 \pm 0.20$ and $4.59 \pm 0.23$, respectively). Meanwhile, the comparison between the time levels of the growth rate in Table 2 shows highly significant differences between all-time levels with the highest mean time at 27 hours $(1.97 \pm 0.01)$ and lowest at zero hours $(0.22 \pm 0.03)$ whereas $\mathrm{pH}$ at 33 hours was the highest values $(3.70 \pm 0.01)$ and the lowest values at zero hours $(5.56 \pm 0.05)$.

Meanwhile, Table 4 displayed the highest survival rate of strain KLDS 1.0373 at 3 hours and $0.3 \%$ of bile salts $\left(1.97 \pm 0.07^{\mathrm{b}}\right)$. Moreover, the lowest survival rate in KLDS 1.0727 after 9 hours and $2 \%$ of bile $(1.78 \pm 0.07)$. Otherwise, the effect of bile salts concentration on growth rate and $\mathrm{pH}(\mathrm{P}$ $<0.001)$ was observed, and there was a significant correlation between the growth rate of strains and $\mathrm{pH}$ values (0.97). In addition, according to Table 2, there was a little significant difference between two strains. KLDS 1.0727 showed higher growth rate and $\mathrm{pH}$ values than KLDS 1.0373, $0.79 \pm 0.08$ and $0.76 \pm 0.08 ; 4.90 \pm 0.10$ and $4.92 \pm 0.10$, respectively.

As Duncan's multiple range test mentioned above, the comparison between time levels of growth rate showed highly significant differences between all-time levels with the highest $\mathrm{pH} 1.40$ and the lowest 1.10. Furthermore, Table 3 showed the highest $\mathrm{pH} 4.11$ and the lowest 5.80. Table 2 showed the comparison between the concentration levels of the growth rate that explained high significant differences between all categories of bile concentration with the highest mean in zero \% of the bile $(1.08 \pm 0.15)$ and was lower at $2 \%$ $(0.52 \pm 0.07)$ while $\mathrm{pH}$ with the highest values in zero $\%$ (4.60 $\pm 0.16)$ and lowest in $2 \%$ of bile $(5.21 \pm 0.10)$.

3.4. Resistance of KLDS 1.0727 and KLDS 1.0373 to Different Types of Antibiotics. Sensitivity to antibiotics is the most important factor in assessing the safety of probiotics and affecting the growth rate of strains and $\mathrm{pH}$. Moreover, it is a potential threat to vital applications [33]. Figure 3 showed the effect of different types of antibiotics on the viability of Lactobacillus brevis strains. The obtained data in Table 2 referring to all factors and all possible interactions were highly significant $(\mathrm{P}<0.001)$. The correlation between bacterial growth rate and $\mathrm{pH}$ values (0.99) was highly significant as well. KLDS 1.0373 showed high growth rate and $\mathrm{pH}$ than KLDS 1.0727, $0.45 \pm 0.06$ and $0.44 \pm 0.06$ for growth rate; $5.33 \pm 0.06$ and $5.32 \pm 0.06$ for $\mathrm{pH}$, respectively. Time levels showed significant differences between all-time categories with the highest growth rate at 24 hours $(0.10 \pm 0.15)$ and the lowest values at 3 hours $(0.05 \pm 0.003)$. Additionally, Table 3 showed the highest $\mathrm{pH}$ values at zero time $(5.74 \pm 0.01)$ and the lowest values at 24 hours $(4.55 \pm 0.14)$. Antibiotics showed highly significant differences between all antibiotics with the highest growth rate of control $(0.80 \pm 0.14)$ and the lowest in ampicillin $(0.05 \pm 0.003)$ and the same results for $\mathrm{pH}$ with the highest $\mathrm{pH}$ in chloramphenicol $(5.71 \pm 0.01)$ and the lowest in control $(4.97 \pm 0.14)$. It is expected since when LAB did not grow, there is no lactic acid production and vice versa.

Table 4 showed the factors affecting survival rate was significant as well as the interaction between the factors $(\mathrm{P}<0.0001)$. KLDS 1.0373 showed the highest survival at 3 hours of streptomycin $(1.61 \pm 0.01,2.75 \pm 0.02$, and 2.36 


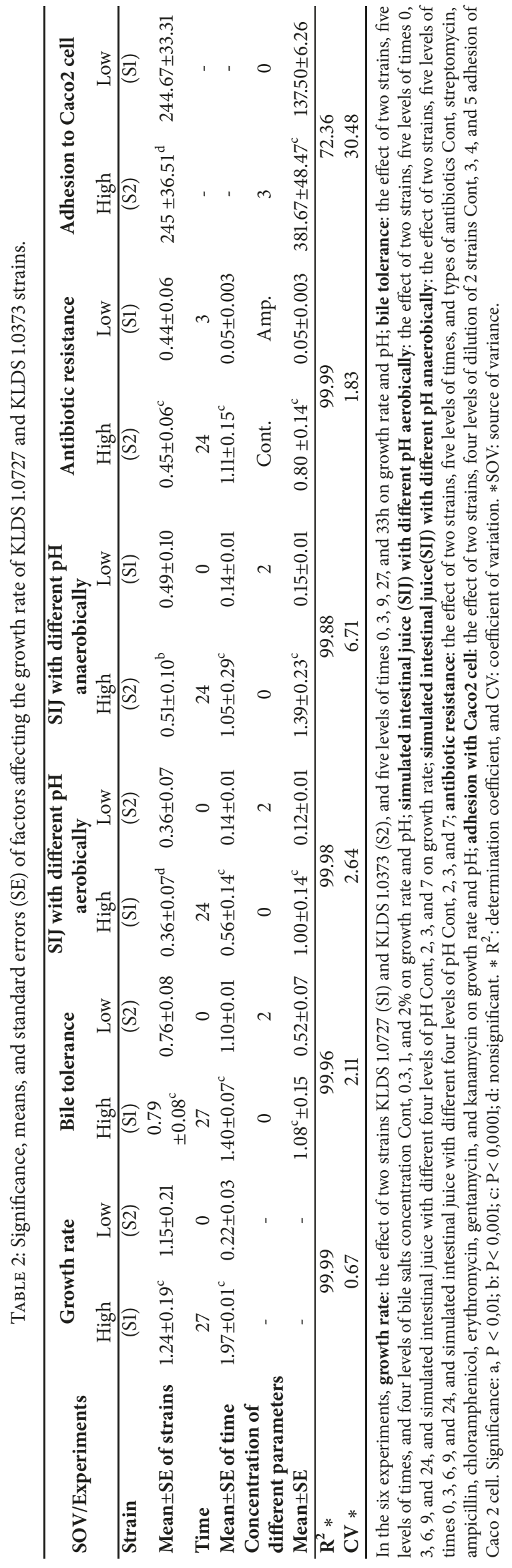




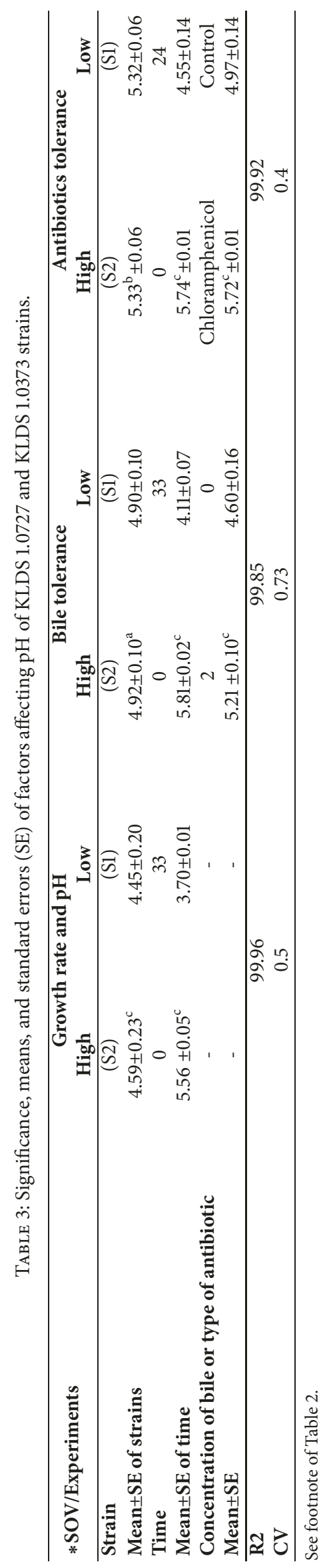




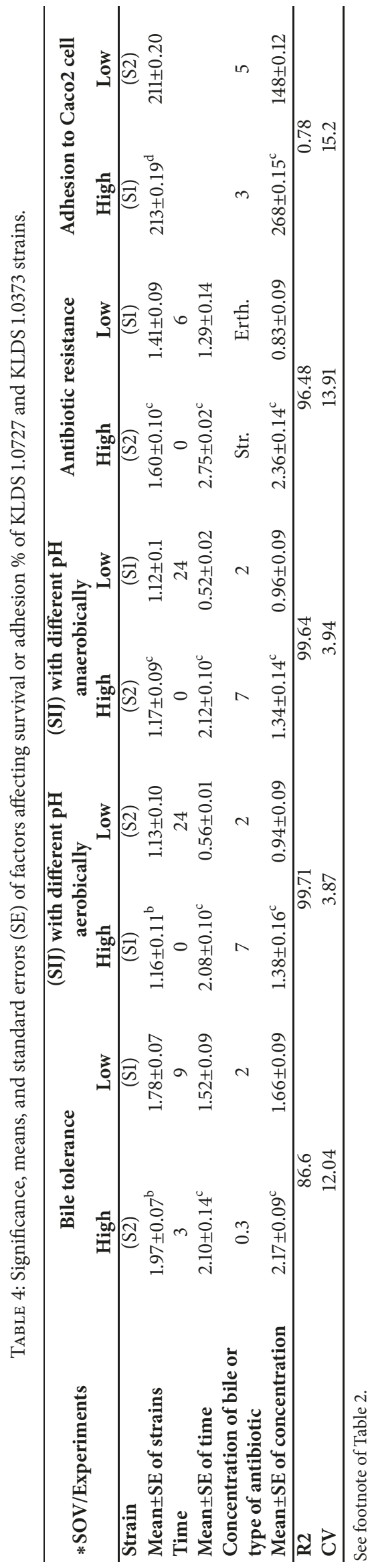



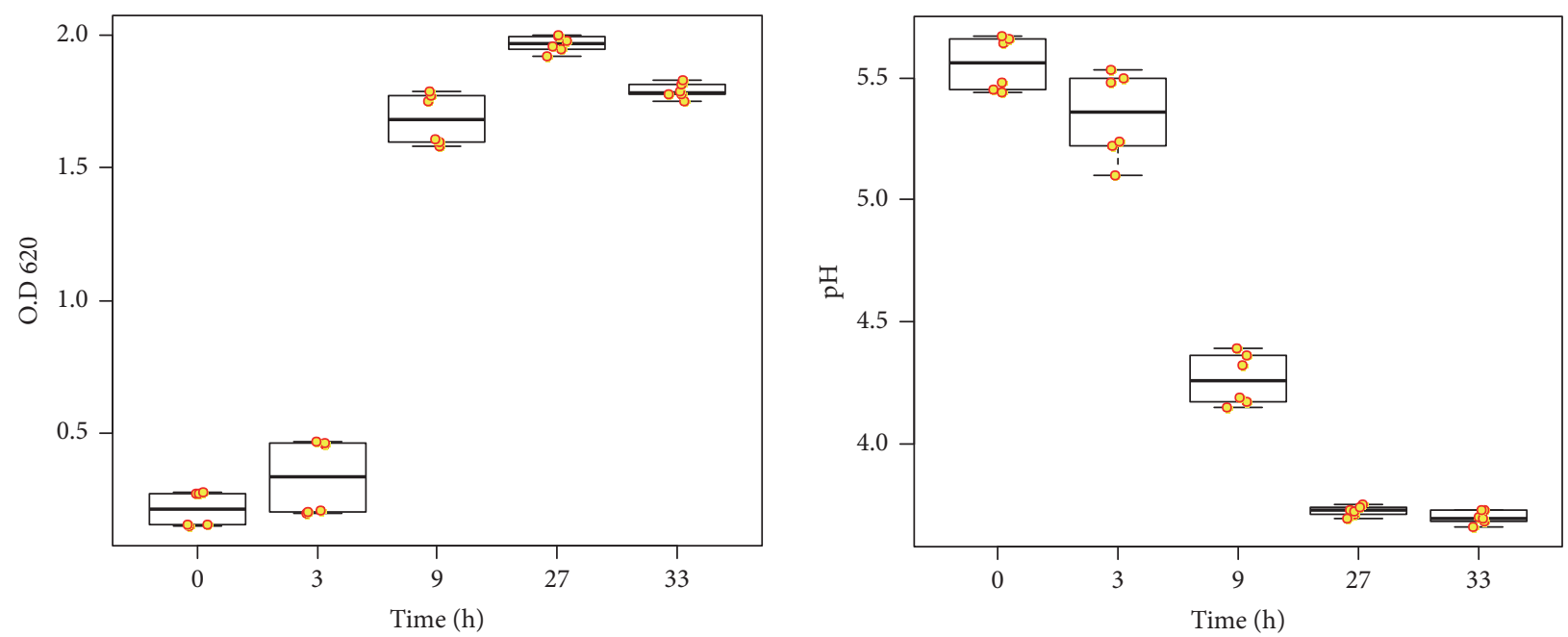

(a)
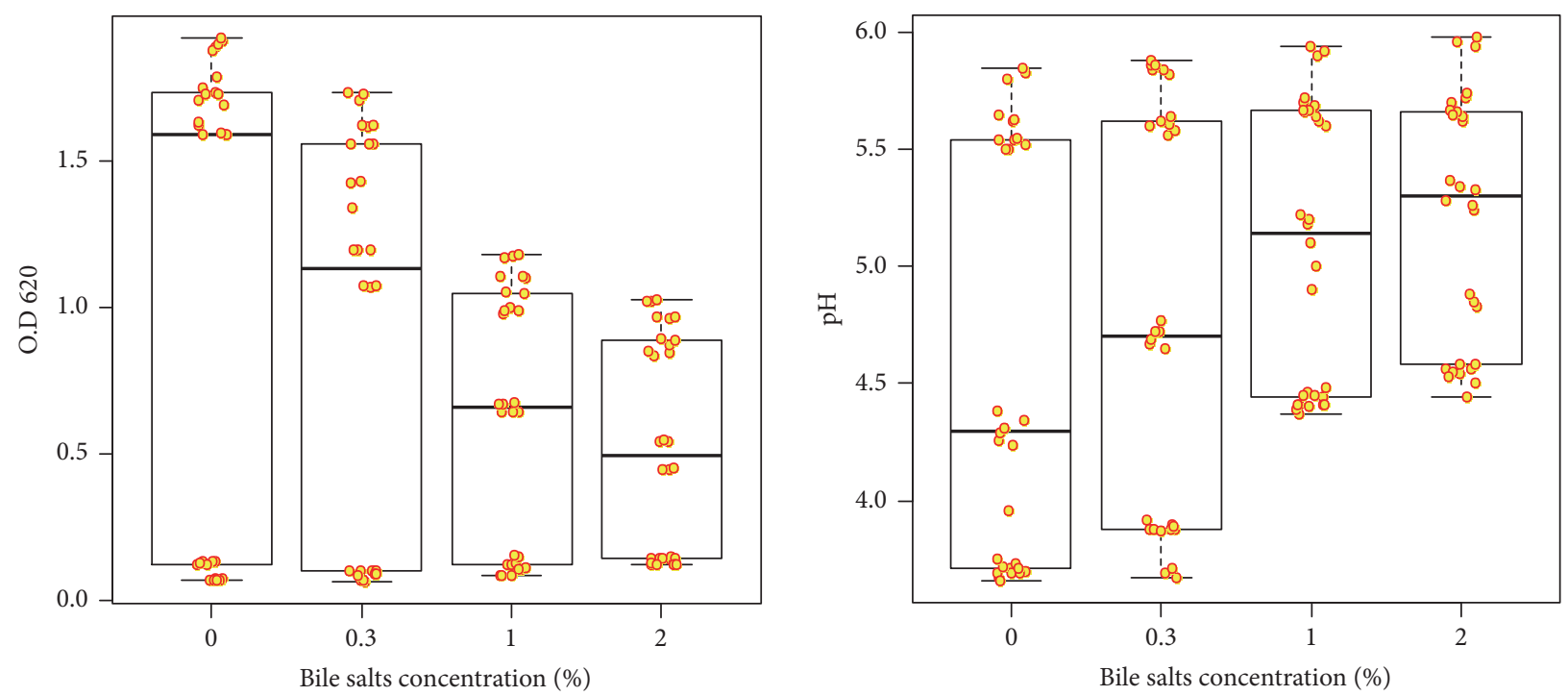

(b) Bile concentration $(0 ; 0.3 ; 1 ; 2 \%)$

FIGURE 2: Determining a standard curve for growth rate/hours and tolerant bile $(0 ; 0.3 ; 1,2 \%)$ with accumulated acid of KLDS 1.0727 and KLDS 1.0373 strains. (a) Growth rate and $\mathrm{pH}$; (b) bile salts and $\mathrm{pH}$.

\pm 0.14 , respectively). Meanwhile, erythromycin showed the lowest effect on strain KLDS 1.0727 at 6 hours $(1.41 \pm$ $0.09,1.29 \pm 0.14$ and $0.83 \pm 0.09$ respectively). Notably, the sensitivity of KLDS 1.0727 after 24 hours to ampicillin, chloramphenicol, and erythromycin was 97.46, 97.91, and 98.11\%, respectively. Further, KLDS 1.0373 was 98.81, 98.38, and $98.61 \%$, respectively. On the other hand, the sensitivity of KLDS 1.0727 after 6 hours to streptomycin, gentamicin, and kanamycin was $12.18,69.64$, and $66.22 \%$, respectively, and KLDS 1.0373 showed $2.28,41.82$, and 11.40, respectively.

3.5. Tolerance KLDS 1.0727 and KLDS 1.0373 to Simulated Intestinal Juice (SIJ) with Different $p H$ under Aerobic or Anaerobic Conditions. The tolerance of GIT conditions is an important criterion for the selection of potential probiotics. Several studies have reported that MRS broth with $\mathrm{pH}$ value (2.0 - 3.0) was used to determine Lactobacillus acid resistance
$[34,35]$. Figure 4 shows the stander curve of the growth rate of KLDS 1.0727 and KLDS 1.0373 to tolerate (SIJ) with different levels of $\mathrm{pH}$ under aerobic or anaerobic condition. The data showed no significant effect $(\mathrm{P}<0.05)$ growth rate of strains. However, the time and different $\mathrm{pH}$ and their interaction were extremely high $(\mathrm{P}<0.001)$. Table 2 indicates that the highest growth rate at 24 hours aerobically in control without any addition of (SIJ) was $(0.56 \pm 0.15$ and $1.00 \pm$ 0.14 , respectively), and the lowest growth rate at zero time with pH 2.0 was $(0.14 \pm 0.01$ and $0.12 \pm 0.01$, respectively). The obtained data in Table 4 showed that the growth rate and interaction between the factors were very significant $(\mathrm{P}$ $<0.0001)$. The Duncan groups showed the highest survival rate for KLDS 1.0727 at zero time and pH 7.0 (1.16 $\pm 0.11 ; 2.08 \pm$ 0.10 , and $1.38 \pm 0.16$ respectively). Meanwhile, KLDS 1.0373 at $\mathrm{pH} 2.0$ showed lower survival rate $(1.13 \pm 0.10 ; 0.56 \pm 0.01$ and $0.94 \pm 0.09$, respectively). These results were consistent with 

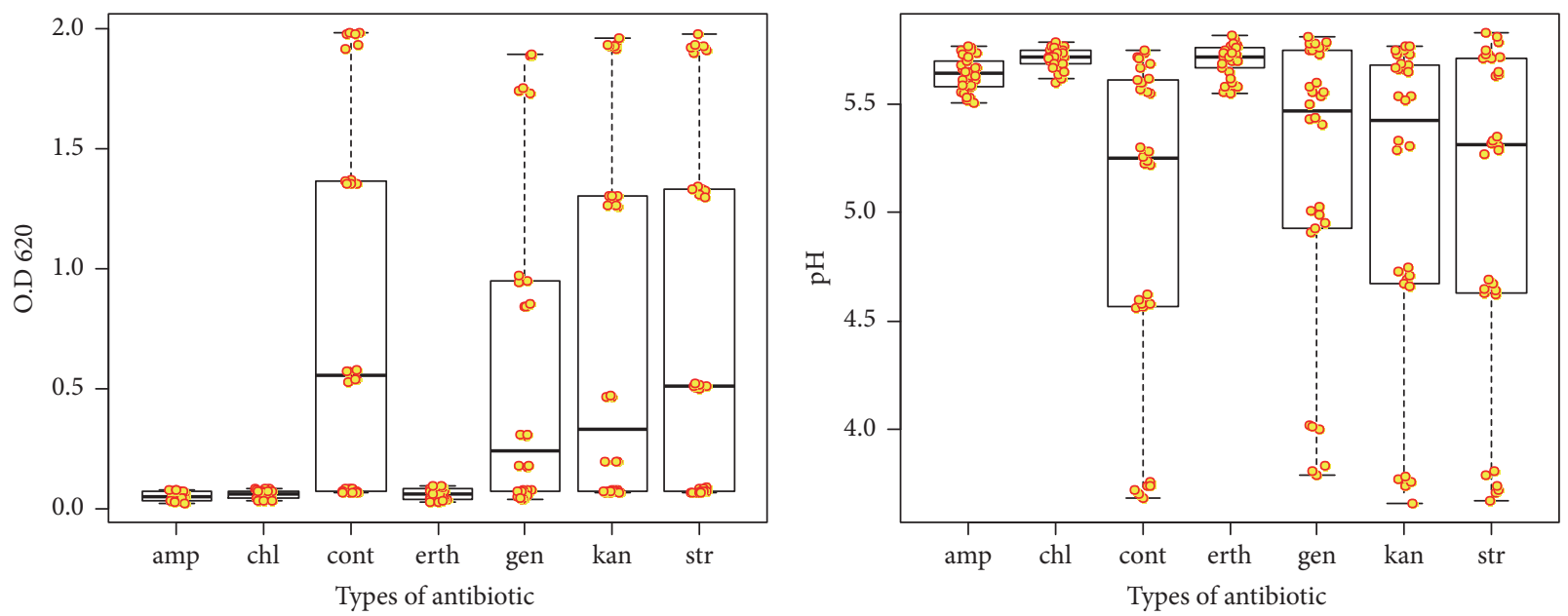

FIgURE 3: Resistance of KLDS 1.0727 and KLDS 1.0373 to different types of antibiotic as (OD) ${ }_{620}$ or pH. (amp), ampicillin; (chl), chloramphenicol; (cont), control; (erth), erythromycin; (gen), gentamicin; (kan), kanamycin; and (str), streptomycin.
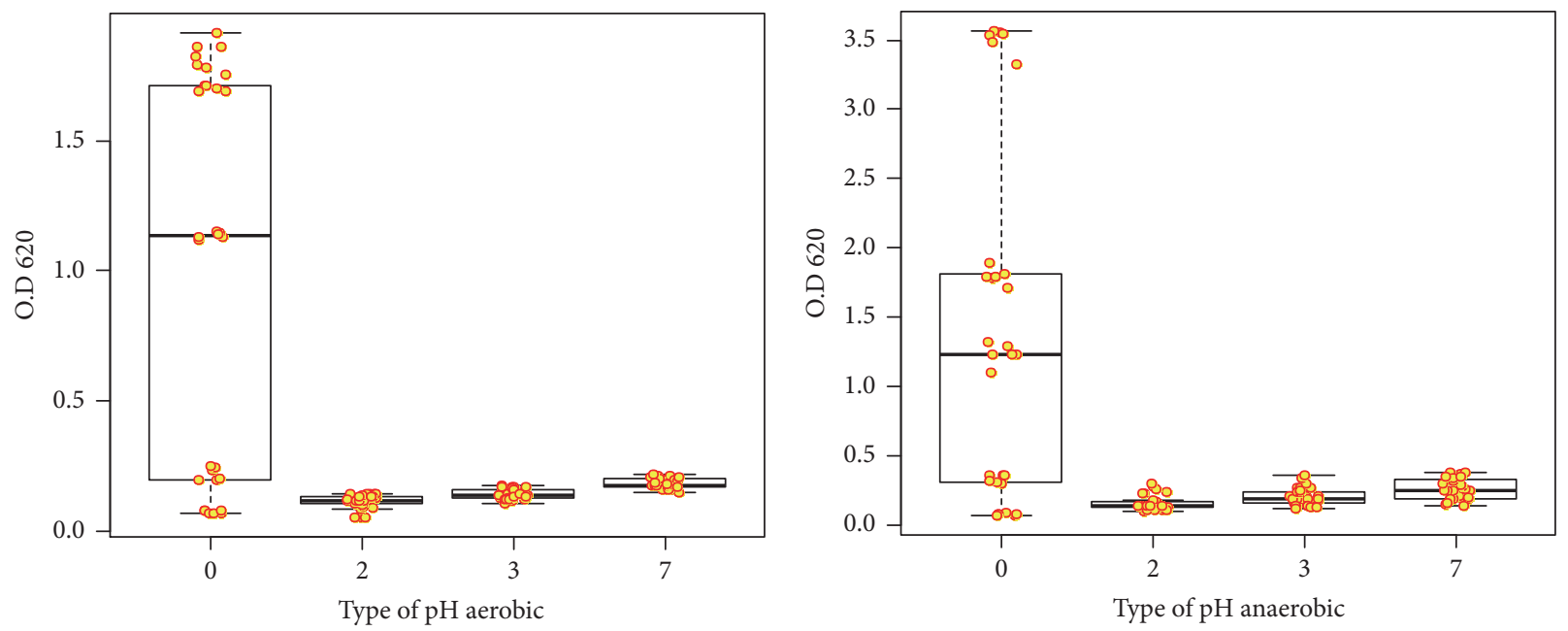

FIgURE 4: Tolerance of KLDS 1.0727 and KLDS 1.0373 to simulated intestinal juice (SIJ) with different $\mathrm{pH}$ under aerobic or anaerobic conditions.

those obtained by de Almeida Júnior et al. [36]. On the other hand, Table 2 showed significant differences between strains and time under anaerobic condition with different factors $(\mathrm{P}<0.001)$ and the significant interaction between them $(\mathrm{P}$ $<0.05)$ KLDS 1.0373 at 24 hours in $\mathrm{pH}$ control showed the highest growth rate $(0.51 \pm 0.10,1.05 \pm 0.29$ and $1.39 \pm 0.23$, respectively). However, KLDS 1.0727 strain at zero time and $\mathrm{pH} 2.0$ values were the lowest $(0.49 \pm 0.10,0.14 \pm 0.01$ and $0.15 \pm 0.01$, respectively). Furthermore, Table 4 showed the survival rate was influenced by the same factors $(\mathrm{P}<0.0001)$. The highest survival rate of the KLDS 1.0373 at zero time and pH 7.0 was $1.17 \pm 0.09,2.12 \pm 0.10$ and $1.34 \pm 0.14$, respectively, while the survival rate of KLDS 1.0727 was the lowest at 24 hours and pH $2.0(1.12 \pm 0.10,0.52 \pm 0.02$ and $0.96 \pm 0.09$ respectively).

3.6. Screening of the Antagonistic Properties of Lactobacillus brevis KLDS 1.0727 and KLDS 1.0373 Strains against Foodborne Pathogenic Bacteria. Due to the biological diversity functions of probiotic bacteria, there is a growing need for new strains of the LAB to play an important role in identifying dominant bacterial communities within intestinal ecosystem [35]. In this study, KLDS 1.0727 and KLDS 1.0373 have been tested against some foodborne pathogens, namely, Salmonella typhimurium ATCC 14028, E. coli IQCC 10126, Listeria monocytogenes IQCC 22221, and Staphylococcus aureus IQCC 22035. Table 5 showed the strongest antimicrobial activity of KLDS 1.0727 and KLDS 1.0373 strains against all the indicator pathogens as expressed in terms of diameter of clear zones $(\mathrm{mm})$. Therefore, the clear zone ranging from $(1.93 \pm 0.07$ to $2.47 \pm 0.03 \mathrm{~mm}$ ) against all test indicators.

3.7. Caco-2 Cell Adhesion Assay. The most important considerations for the selection of probiotics are not only the ability to survive and transit through the digestive system but also the adhesion, establishment, or reproduction within the gastrointestinal tract. The obtained results in Figure 5 (A) showed that the adhesion \% of the KLDS 1.0727 and 


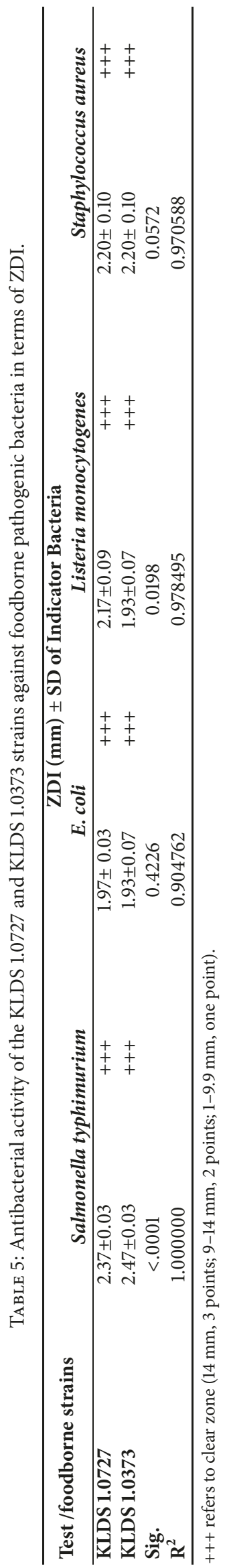




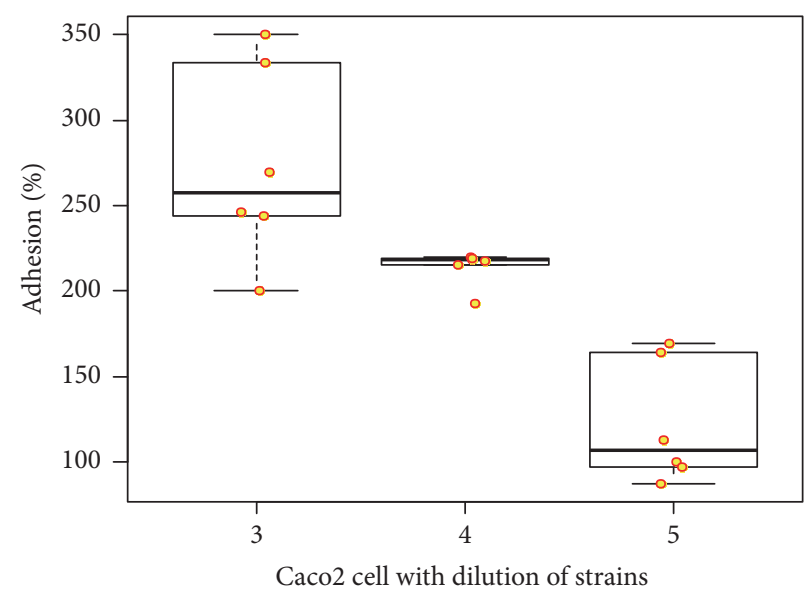

(a) Adhesion \% assay of KLDS 1.0727 and KLDS 1.0373to Caco-2 cell

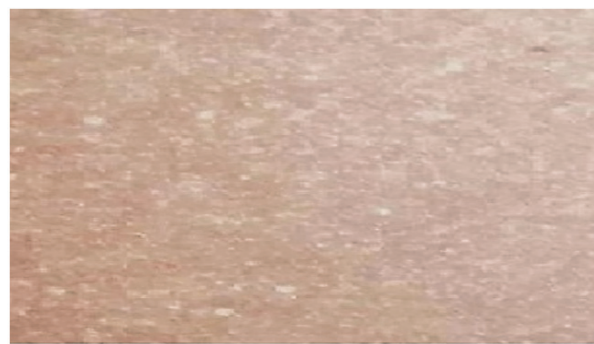

(A)

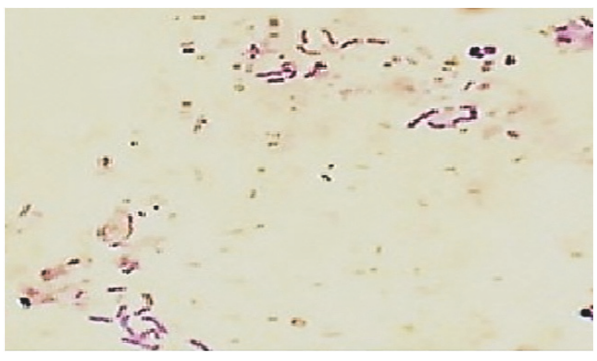

(B)

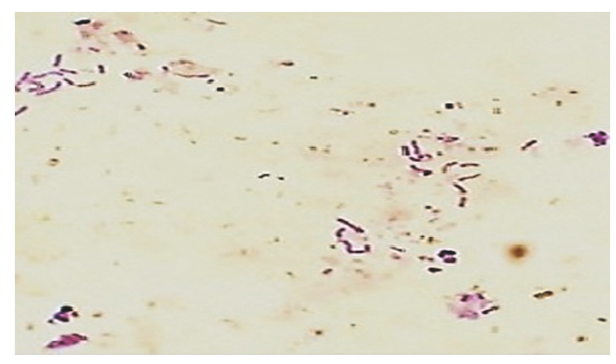

(C)

(b) Determination microscopy adhesion assay of KLDS 1.0727 and KLDS 1.0373 to Caco-2 cell, (A) Caco2 cells control; (B) KLDS 1.0727+ Caco2 cells; (C) KLDS 1.0373+ Caco2 cells

FiguRe 5

KLDS 1.0373 strains was (55.6 - 95.2\%), therefore using three different dilutions KLDS 1.0727 and KLDS 1.0373 strains as $10^{3}, 10^{4}$, and $10^{5}$. Moreover, Table 3 showed the effect of strain types on the adhesion \% was nonsignificant (0.92), while the concentration effect was highly significant $(\mathrm{p}<0.0001)$. KLDS 1.0727 strain in the third dilution fold was the highest adhesion percentage ( $213 \pm 0.19$ and $268 \pm 0.15$, respectively), and KLDS 1.0373 strain in the dilution five was the lowest values $(211 \pm 0.20$ and $148 \pm 0.12$ respectively). Moreover, in Figure 5 (B) microscopic slides showed a high adherence \% of KLDS 1.0727 and KLDS 1.0373 strains.

\subsection{Intervention Effect of KLDS 1.0727 and KLDS 1.0373 Strains on Type I Diabetes In Vivo}

3.8.1. Hypoglycemic Activity and Body Weight of C57BL/6 Mice with Streptozotocin- (STZ-) Induced Diabetes during Four Weeks. Glucose levels and body weight were checked weekly for five treated groups namely (Cont, STZ, STZ+INS; S1, and S2). The obtained results in Figure 6 showed a chronic increase in blood glucose level overnight fasting 12 hours and 2 hours postprandial and body weight within four weeks. The data presented the glucose levels as equation mentioned above for Cont; STZ; INS+STZ; S1; S2 was 4.2675 \pm 1.11 ; $6.595 \pm 1.63, \underline{-5.7375} ; 3.58 \pm 0.94$, and $2.5925 \pm 2.15$, respectively. In addition, the effect of STZ causing diabetes for C57BL/6 mice had a different effect on mice body weight. It was nonsignificant for all completely treated groups. Briefly, the lowest blood glucose and the highest body weight was in (INS+STZ) group (-5.7375; and $21.12 \pm 2.54^{\mathrm{a}}$ respectively). Notably, the (INS + STZ) group showed the blood glucose levels before eating or insulin injection were higher than the blood samples taken 2 hours postprandial. In contrast to all other groups, this may be due to insulin injection that promotes glucose uptake in blood. 


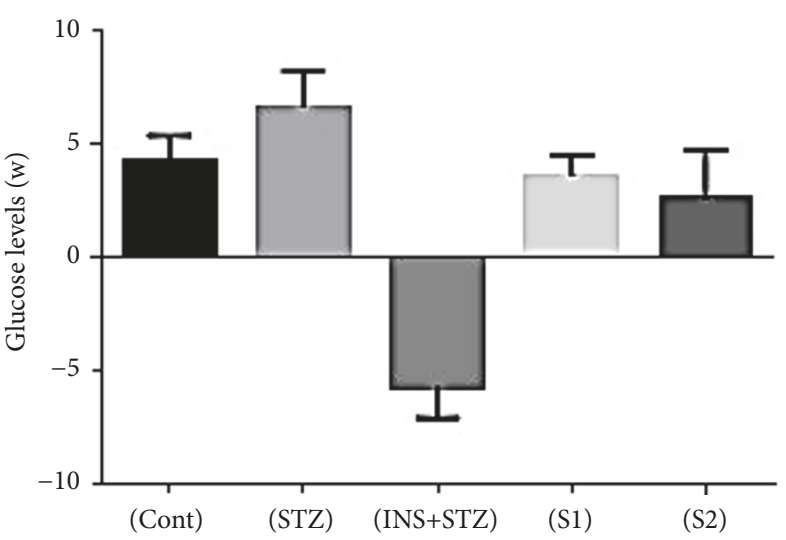

(a)

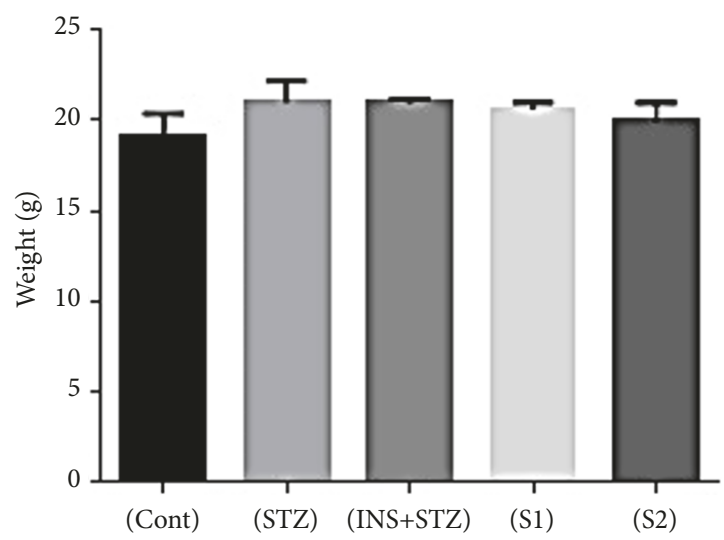

(b)

FIGURE 6: Blood glucose mmol/dl and body weight/g of C57BL/6 mice with streptozotocin- (STZ-) induced diabetes during four weeks. (a) Average of blood glucose level, (b) body weight/g. (Cont), control; (STZ), streptozotocin; (INS+STZ), insulin; (S1), KLDS 1.0727; (S2), KLDS 1.0373 .

\subsection{Blood Plasma Assay}

3.9.1. Serum Biochemistry Parameters Assay. After overnight fasting, mice have been killed and blood serum was collected, and serum biochemistry parameters were measured. Table 6 displayed the serum lipids concentrations as triglyceride (TG); total cholesterol (CHOL); high-density lipoprotein cholesterol (HDL); low-density lipoprotein cholesterol (LDL); glucose (GLU); magnesium $\left(\mathrm{Mg}^{+2}\right)$ as well. All treated groups were highly significant, whereas Cont and STZ showed a high level of TG $(2.54 \pm 0.91$ and $2.06 \pm 0.84 \mathrm{mmol} / \mathrm{L}$, respectively). Notably, all groups displayed a high level of $\mathrm{Mg}^{+2}$ and low level of LDL. Further, Cont group showed the highest level of CHOL $\left(7.25 \pm 0.93^{\mathrm{b}}\right)$. On the other hand, INS+STZ showed the highest level of glucose $\left(9.40 \pm 3.84^{\mathrm{b}}\right)$. Worthy of notice, S1 falls within the reference range of TG, CHOL, HDL, LDL, and GLU. Therefore, it can conclude that Cont showed the highest level of TG, CHOL, HDL, and LDL, while STZ showed the highest level of $\mathrm{Mg}^{+2}$, Moreover, INS+STZ showed the lowest level of CHOL and $\mathrm{Mg}^{+2}$ and the highest level of GLU. On the contrary, S1 expressed the lowest level of TG, LDL, and GLU.

3.10. Liver Functions Parameters. Liver functions parameters evaluated were the serum alanine aminotransferase (ALT); aspartate transaminase (AST); AST/ALT; total bile acid (TBA); albumin (ALB); globulin (GLUB); total protein (TP). Table 6 showed (TP) total protein of all treated experiments falls in the average reference range except STZ that was $(84.90 \pm 34.66)$. (ALT) serum alanine aminotransferase showed a dramatic increase in all treated groups and out of average reference range except (S2), $(36.00 \pm 14.70)$. In addition, (AST) aspartate aminotransferase showed a significant increase in the levels of all treatment groups and also exceeded the mean of the reference range. Further, total bile acid (TBA) was expressed at a reasonable level for all treated groups, while albumin (ALB) and globulin (GLUB) display results are coherent for all treated groups where it falls in the average of the reference range. Briefly, STZ showed the highest level of TP, AST, ALB, and GLUB compared to all treated groups.

3.11. Kidney Function Parameter. Table 6 determined the kidney functions parameters such as uric nitrogen (BUN), creatinine (CREA), and uric acid (URIC) levels. The results displayed not alarming increase in uric nitrogen (BUN) and, further, creatinine (CREA) and uric acid (URIC) levels as well. All treated groups fall in the average of the reference range except Cont and S1 which expressed the lowest level of uric acid (URIC) $\left(76.50 \pm 31.23^{\mathrm{b}}\right.$ and $125.60 \pm 51.28^{\mathrm{ab}}$, respectively).

3.12. Insulin Blood Plasma Assay. Table 6 exhibited that all the treated groups fall within the reference range average. Therefore, Cont and S1 displayed the heights of groups in insulin levels as $13.52 \pm 0.23$ and $11.13 \pm 0.28$, respectively. Meanwhile, STZ and INS+STZ expressed the lowest levels as $9.99 \pm 0.36$ and $10.60 \pm 0.21$, respectively.

3.13. Histological Evaluation. The slides in Figure 7 exhibited the histological mice organs (namely, liver; pancreas, kidney, and spleen). The figure illustrates that the livers histology of different groups as follows, no abnormal morphology in Cont or STZ groups, while INS+STZ showed a slight denatured and a little fat. Further, S1 group was hepatic nucleus and shrunk as well. S2 shows a combination of mild fatty degeneration of the liver and inflammatory cells collected piles of diffuse inflammatory cells. Moreover, the pancreas histology exhibited that there was no abnormal morphology in the Cont while STZ was a significant atrophy in pancreatic islets cells with a huge vacuolar degeneration. INS+STZ, S1, and S2 groups showed a mild integration. The kidneys histological slides displayed that Cont has no abnormal morphology, STZ group was atrophy, and glomerular shrinkage is evident in the renal tube fused obviously. Further, the state of INS+STZ and S1 glomerulus is normal, renal tubule fused slightly, 


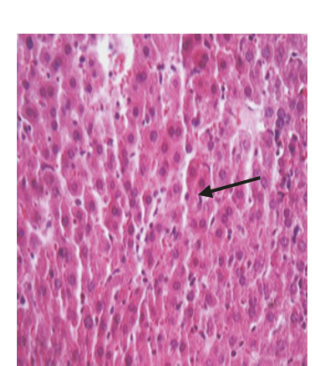

(Cont)

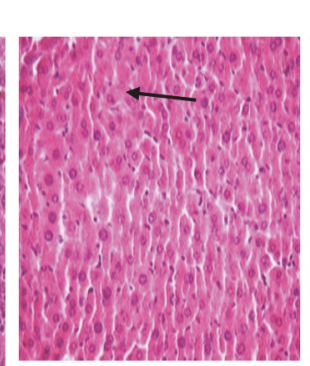

(STZ)

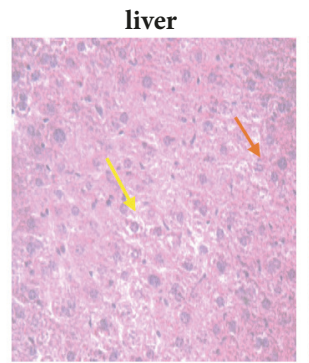

(INS+STZ)

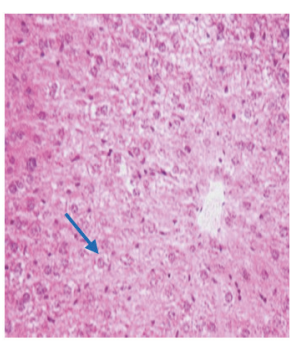

(S1)

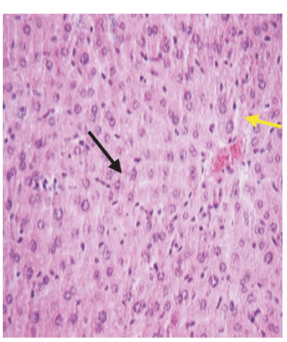

(S2)

(Cont or STZ), No abnormal morphology (black arrow); (INS+STZ) show a slight denatured (orange arrow) and a little fat (yellow arrow), (S1) has hepatic nucleus and shrunk (blue arrow), (S2) Combination of mild fatty degeneration of the liver (yellow arrow) and inflammatory cells collected piles of diffuse inflammatory cells (black arrow)

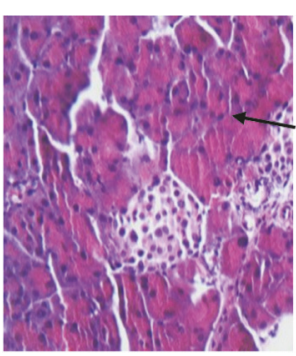

(Cont)

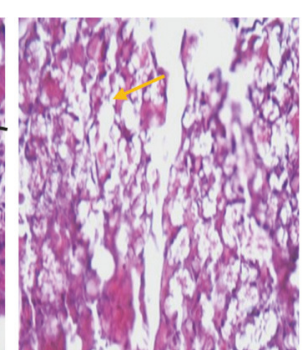

(STZ)

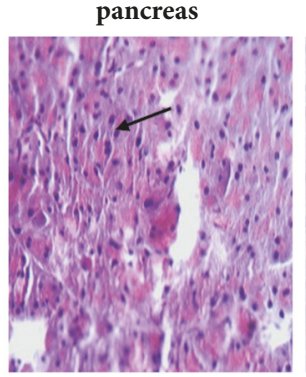

(INS+STZ)

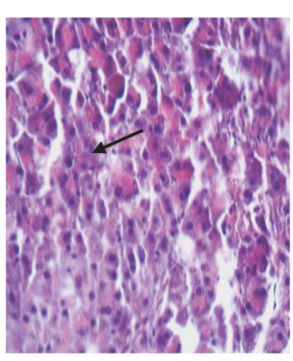

(S1)

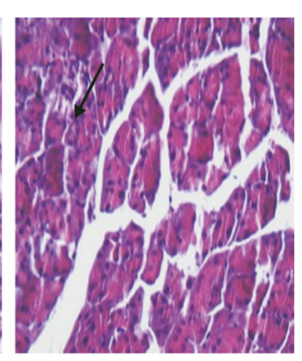

(S2)

(Cont.), no abnormal morphology (black arrow); (STZ), large atrophy (orange arrow); (INS+STZ; S1, and S2) groups show a mild integration (black arrow)

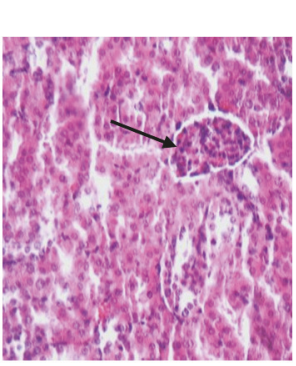

(Cont)

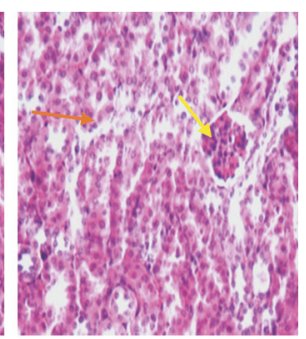

(STZ)

kidney

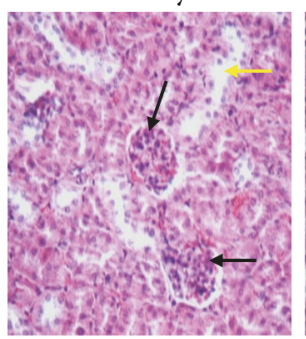

(INS+STZ)

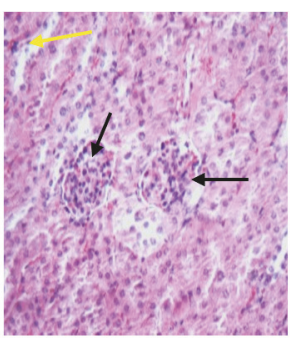

(S1)

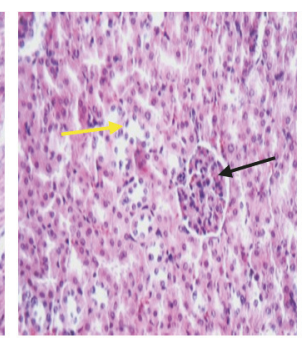

(S2)

(Cont.), no abnormal morphology (black arrow); (STZ) atrophy and glomerular shrinkage is evident in the renal tube fused obviously (orange arrow); (INS+STZ, and S1) the state of glomerulus is normal (black arrow), renal tubule fused slightly (yellow arrow), and (S2), no abnormal morphology (black arrow) renal tubule fused slightly (yellow

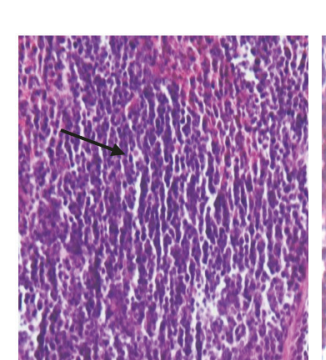

(Cont)

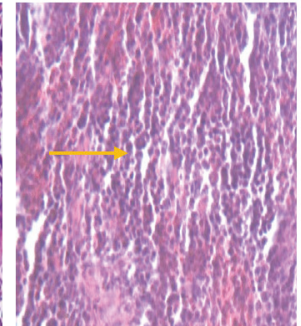

(STZ)

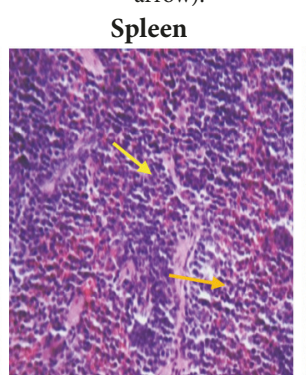

(INS+STZ)

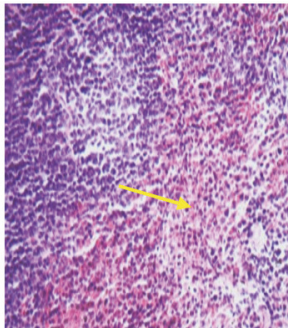

(S1)

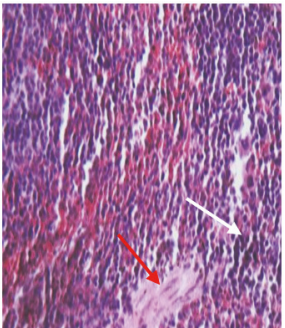

(S2)

(Cont.) no abnormal appearance (black arrow); (STZ) lymphocytes number were reduced and their structures are lost ( orange arrow), (INS+STZ) a trabecular increase (yellow arrow) and lymphatic decrease (orange arrow). (S1), the number of lymphocytes was reduced (yellow arrow) ; (S2) Spleen trabecular (white arrow) and Phagocyte was increased (red arrow).

FIGURE 7: Histological examination of sacrifice mice organs (liver; pancreas; kidney, and spleen) streptozotocin-induced diabetes. (Cont), control; (STZ), streptozotocin; (INS+STZ), insulin; (S1), KLDS 1.0727, and (S2), KLDS 1.0373. 
TABLE 6: Blood plasma assay $(n=4$, mean \pm SE).

\begin{tabular}{|c|c|c|c|c|c|c|}
\hline & Ref. ranges & (Cont) & (STZ) & $(\mathrm{INS}+\mathrm{STZ})$ & (S1) & (S2) \\
\hline & \multicolumn{6}{|c|}{ Plasma biochemical parameter } \\
\hline TG mmol/Lb** & $0.45-1.7$ & $2.54 \pm 0.91$ & $2.06 \pm 0.84$ & $1.02 \pm 0.42$ & $0.96 \pm 0.39$ & $1.34 \pm 0.55$ \\
\hline CHOL mmol/L"** & $2.85-5.7$ & $7.25 \pm 0.93^{b}$ & $4.89 \pm 2.00^{\mathrm{bc}}$ & $3.38 \pm 1.38^{\mathrm{c}}$ & $3.46 \pm 1.41^{\mathrm{c}}$ & $3.44 \pm 1.40^{\mathrm{c}}$ \\
\hline $\mathrm{HDL} \mathbf{m m o l} / \mathrm{L}^{*}$ & $0.93-1.81$ & $4.20 \pm 0.90^{\mathrm{a}}$ & $1.55 \pm 0.63^{\mathrm{b}}$ & $2.26 \pm 0.92^{\mathrm{b}}$ & $2.39 \pm 0.98^{\mathrm{b}}$ & $2.22 \pm 0.91^{\mathrm{b}}$ \\
\hline LDL $\mathrm{mmol} / \mathrm{L}^{\mathrm{ns}}$ & $2.07-3.63$ & $1.14 \pm 0.47^{\mathrm{a}}$ & $0.83 \pm 0.34^{\mathrm{ab}}$ & $0.49 \pm 0.20^{\mathrm{b}}$ & $0.38 \pm 0.16^{\mathrm{b}}$ & $0.48 \pm 0.20^{\mathrm{b}}$ \\
\hline $\mathrm{Mg}^{+2} \mathrm{mmol} / \mathrm{Lb}^{*}$ & $0.7-1.1$ & $1.50 \pm 0.08$ & $1.75 \pm 0.71$ & $1.48 \pm 0.60$ & $1.64 \pm 0.67$ & $1.64 \pm 0.67$ \\
\hline GLU mmol/L L $^{* *}$ & $3.57-6.12$ & $4.4 \pm 1.27^{\mathrm{bc}}$ & $4.40 \pm 1.80^{\mathrm{a}}$ & $9.4 \pm 2.71^{\mathrm{a}}$ & $3.1 \pm 0.89^{c}$ & $5.1 \pm 1.47^{\mathrm{bc}}$ \\
\hline \multicolumn{7}{|c|}{ Liver functions parameters } \\
\hline TP $\mathrm{g} / \mathrm{Lb}^{* * *}$ & $60.0-80.0$ & $60.30 \pm 0.90$ & $84.90 \pm 34.66$ & $58.10 \pm 23.72$ & $60.90 \pm 24.86$ & $64.90 \pm 26.50$ \\
\hline ALT IU/Lb $\mathbf{b}^{* * *}$ & $1.0-40.0$ & $128.00 \pm 0.82$ & $95.00 \pm 38.78$ & $77.00 \pm 31.44$ & $83.00 \pm 33.88$ & $36.00 \pm 14.70$ \\
\hline AST IU/Lb $\mathbf{L}^{* * *}$ & $1.0-40.0$ & $263.00 \pm 0.82$ & $341.00 \pm 139.21$ & $176.00 \pm 71.85$ & $274.00 \pm 111.86$ & $182.00 \pm 74.30$ \\
\hline AST/ALT ${ }^{*}$ & & $2.05 \pm 0.01^{\mathrm{b}}$ & $3.59 \pm 0.01^{\mathrm{ab}}$ & $2.29 \pm 0.01^{\mathrm{b}}$ & $3.30 \pm 1.35^{\mathrm{ab}}$ & $2.89 \pm 1.18^{\mathrm{b}}$ \\
\hline TBA mol/Lb ${ }^{* * *}$ & $0.01-20.0$ & $8.50 \pm 0.90$ & $4.90 \pm 2.00$ & $3.90 \pm 1.59$ & $2.60 \pm 1.06$ & $3.90 \pm 1.59$ \\
\hline ALB $g / L b^{n s}$ & $35.0-55.0$ & $34.50 \pm 0.90^{\mathrm{a}}$ & $39.10 \pm 15.96^{\mathrm{ab}}$ & $33.70 \pm 13.76^{\mathrm{ab}}$ & $36.50 \pm 14.90^{\mathrm{ab}}$ & $37.50 \pm 15.31^{\mathrm{ab}}$ \\
\hline GLUB $\mathbf{g} / \mathbf{L b}^{* * *}$ & $25.0-40.0$ & $25.80 \pm 0.90$ & $45.80 \pm 18.70$ & $24.40 \pm 9.96$ & $24.40 \pm 9.96$ & $27.40 \pm 11.19$ \\
\hline $\mathrm{A} / \mathrm{G}^{\mathrm{ns}}$ & $1.5-2.5$ & $1.34 \pm 0.01^{\mathrm{a}}$ & $0.85 \pm 0.01^{\mathrm{ab}}$ & $1.38 \pm 0.01^{\mathrm{a}}$ & $1.50 \pm 0.61^{\mathrm{a}}$ & $1.37 \pm 0.56^{\mathrm{a}}$ \\
\hline \multicolumn{7}{|c|}{ Kidney function parameter } \\
\hline BUN mmol/Lb ${ }^{* * *}$ & $1.07-7.14$ & $8.60 \pm 3.51$ & $10.50 \pm 4.29$ & $8.00 \pm 3.27$ & $11.80 \pm 4.82$ & $10.80 \pm 4.41$ \\
\hline CREA mol/Lb ${ }^{* * *}$ & $53.0-132.0$ & $44.30 \pm 18.09$ & $40.50 \pm 16.53$ & $39.10 \pm 15.96$ & $37.40 \pm 15.27$ & $41.90 \pm 17.11$ \\
\hline${\mathrm{URIC} \mathrm{Umol} / \mathrm{L}^{\mathrm{ns}}}^{\mathrm{U}}$ & $142.0-401.0$ & $76.50 \pm 31.23^{\mathrm{b}}$ & $175.10 \pm 71.48^{\mathrm{ab}}$ & $180.60 \pm 73.73^{\mathrm{ab}}$ & $125.60 \pm 51.28^{\mathrm{ab}}$ & $164.90 \pm 67.32^{\mathrm{ab}}$ \\
\hline \multicolumn{7}{|c|}{ Insulin blood plasma } \\
\hline Insulin $\mathrm{uIU} / \mathrm{ml}$ & 3-19 & $13.52 \pm 0.23$ & $9.99 \pm 0.36$ & $10.60 \pm 0.21$ & $11.13 \pm 0.28$ & $10.93 \pm 0.20$ \\
\hline
\end{tabular}

and S2 has no abnormalities. Finally, the spleens histology exhibited that Cont has no abnormal appearance. Meanwhile, STZ group displayed lymphocytes number reduced and their structures are lost. Obviously, INS+STZ showed a trabecular increase and lymphatic decrease and the number of lymphocytes obviously reduced in S1, whereas S2 demonstrates that the spleen trabecular and phagocyte were increased.

\section{Discussion}

One of the key terms of probiotics is that they must withstand the harsh conditions of gastrointestinal juices, and, further, the ability to survive in the presence of bile, pancreatic juice, until the intestine is sufficient in number and provides health benefits for the host $[37,38]$. In this study, two strains of Lactobacillus brevis were genetically determined and tested in vitro for some inappropriate simulated gastrointestinal conditions, such as acidity, bile tolerance, antibiotic resistance, and antimicrobial activity. Furthermore, in vivo experiments such as blood glucose; body weight; blood plasma; histological assay were tested to demonstrate the role of Lactobacillus brevis strains in the intervention of type 1 diabetes.

Lactobacillus brevis KLDS 1.0727 and KLDS 1.0373 is Gram-positive of lactic acid bacteria, which is a rod-type strain with high GABA generating capacity due to the gad gene. To confirm the identification of KLDS 1.0727 and KLDS 1.0373 strains, 16S rDNA was amplified and $540 \mathrm{bp}$ of the DNA sequence was determined (unpublished data). The GenBank database was used to search for genes as the $16 \mathrm{~S}$ rDNA sequence that revealed the highest similarity in the nucleotide chain was $99 \%$ with L. brevis (GenBank access no AF515220) and L. brevis (GenBank access no. AF515219). Therefore, the strains KLDS 1.0727 and KLDS 1.0373 are one of $L$. brevis strains.

The basic logistics model of SAS software suitable for experimental data showed that the factors (strains, time, and interaction between them) had significant effects on the growth rate of KLDS 1.0727 and KLDS 1.0373 strains and $\mathrm{pH}$ values $(\mathrm{P}<0.0001)$. Therefore, the obtained data were consistent with Liao et al. [39] who reported that $\mathrm{pH}$ values declined dramatically rapid in the first 9 hours and then slowly declined, attributed to strains that reached the stationary phase. In general, LAB growth reaches the stationary phase when the $\mathrm{pH}$ is less than 4.5 . Zhang and Yew [40] reported that the acid resistance of LAB strains is dependent on specific strains and species.

Lactobacillus brevis strains were examined and tested for resistance and survival in acidic environment, as well as for growing in the presence of $0.3-2 \%$ bile salts; a similar concentration was found in the small intestine [41]. The obtained results showed Lactobacillus brevis strains were able 
to grow in high bile concentrations (2\%). Similar results were previously reported by other researchers to study vital LAB strains from different environments [42]. The resistance of KLDS 1.0727 and KLDS 1.0373 strains of bile salts in MRS incubated at $37^{\circ} \mathrm{C}$ with $0.3 \%$ concentration of bile salts was closely related to bile level as reported by Sahadeva et al. [38]. In the gastrointestinal tract, observations were common between comparing different strains and different concentrations of bile, such as $0.3,1$, and $2 \%$. These concentrations were closely associated with Hyacinta et al. [43] who explained the vitality of microorganisms affected by concentrations of bile salts.

Antibiotic is one of the most important growth determinants of most microbes and their resistance to growth is a criterion for selection of probiotic bacteria. Therefore, in the present study, the obtained data were in agreement with Klare et al. [44] who confirmed that LAB is usually sensitive to antibiotics such as chloramphenicol. de Almeida Júnior et al. [36] studied that $96 \%$ of disabling strains were sensitive to chloramphenicol. Furthermore, our findings were in agreement with Tulumoglu et al. [35] who reported that $90 \%$ of the tested Lactobacillus strains were resistant to gentamicin; meanwhile other studied strains were sensitive to ampicillin and erythromycin.

Lactobacillus brevis strains are a facultative anaerobic or microaerophilic LAB. Therefore, these explain our obtained results. Wu and Shah [45] concluded that ventilation has a bad effect on the feasibility and production of lactic acid and GABA by Lactobacillus brevis. The obtained results were consistent with those of Zhang [46], who showed the performance of antiacids of isolated strains. In addition, $\mathrm{Wu}$ et al. [19] reported that pancreatic fluid had no significant effect on survival of LAB.

Lactic acid bacteria have extremely antagonists against foodborne pathogenic bacteria [47]. Gautam and Sharma [48] report similar studies with Lactobacillus spicheri G2 showing $60 \%$ of hostility against different test indicators. Further, the obtained results were closely correlated with the findings of Fossi et al. [49]. A number of studies reported the potential antimicrobial mechanisms of specific microorganisms for the control pathogens are indicated as (i) production of antimicrobial compounds, (ii) production of bacteriocins, (iii) competitive action on nutrients, (iv) inhibition of binding due to competition, and (v) formation of the immune system [50]. Moreover, these findings agreed with our obtained results that show an extremely antagonism against common foodborne pathogenesis.

The adhesion of the intestinal mucosa is one of the most important features of probiotic bacteria to reproduction and produce biological compounds in the host digestive system [51]. LAB adhesion is a complex process involving the communication between the bacterial cell membrane and the interacting surfaces. Ehrmann et al. [52] reported that the ability of LAB to adhere to other cells is related to cell surface charge and hydrophobicity of bacteria. The ability to hold hydrocarbons can be expressed as cell surface hydrophobicity [53]. Moreover, Solieri et al. [34] reported that the hydrophobicity above $70 \%$ is considered highly hydrophobic. The obtained results were consistent with the study conducted by Zhang [46] who found that the highest hydrophobicity of the strains was $92.15 \%$. Our results showed that KLDS 1.0727 and KLDS 1.0373 have a similar adhesion value to the recognized probiotic strain Lb. rhamnosus GG, suggesting that it may be well-colonized in vivo.

Recently, diabetes has become the most common disease in the world. It causes many complications; hence high blood glucose levels may always damage tissues, especially capillaries and glomerular mesenchymal cells [54]. Streptozotocin (STZ) has been used clinically as a chemotherapeutic agent in the treatment of pancreatic cell $\beta$-cell carcinoma [55]. Reference ranges for blood tests are sets of values used by a health professional to interpret a set of medical test results from blood samples. In addition, examples of reference domains are given, varying by age, sex, health, and ethnicity, a method of analysis and measurement units. Individual results should always be interpreted using the reference range provided by the test laboratory.

Glucose serum (GLU) was reported by Wasserman [56]. The blood glucose test can measure the liver's ability to produce glucose, usually the last function to be lost if the liver fails. Glucose levels are usually the lowest in the morning before the first meal of the day and increase after meals for one to two hours. Blood sugar levels outside the normal range may be indicative of a medical condition. The higher level systematically refers to the high level of blood sugar. Low levels are known as hypoglycemia. Among the most observed cases, the obtained results are in close agreement with American Diabetes Association and Sacks et al. [57, 58] that suggest diabetes diagnosis historically included fasting blood glucose more than $7 \mathrm{mmol} / \mathrm{dL}(126 \mathrm{mg} / \mathrm{dL})$ to $11.1 \mathrm{mmol} / \mathrm{dL}(200 \mathrm{mg} / \mathrm{dL}$ ) or higher with hyperglycemia symptoms, or an abnormal oral glucose tolerance test of 2 hours.

High-density lipoprotein (HDL) is one of the five major groups of lipoproteins. HDL molecules are sometimes referred to as "good cholesterol" because it can transfer fat molecules from artery walls, reduce pharyngeal accumulation, and thus help to prevent or harden atherosclerosis. Therefore, the obtained results displayed that Lactobacillus brevis KLDS 1.0727 and KLDS 1.0373 strains have a slight similarity in the recommended ranges according to the American Heart Association, the National Institutes of Health, and the National Demining Program providing a set of guidelines on HDL levels and cardiovascular risk > $1.55 \mathrm{mmol} / \mathrm{L}$ [59].

Changes in ALT and AST levels are often used for liver pathological examination, AST /ALT is an important biochemical indicator [60]. ALT is mainly present in the liver cell plasma. When the liver cells are less damaged, the changes in membrane permeability of the liver cells will elevate the ALT blood levels. On the other hand, the increased levels of AST blood are the result of severe damage to liver cells. In other words, the higher AST / ALT ratio means more severe damage to liver cells. The findings results were in agreement with Prakasam et al. [61] who reported that the use of streptozotocin increases the level of AST, ALT, and ALP in blood plasma. Furthermore, the obtained results of KLDS 1.0727 and KLDS 1.0373 fall in the reference range and are in close similarity to total protein (TP) level 60.0-80.0 
$\mathrm{gm} / \mathrm{dl}$. Besides, the total serum albumin (ALB) level is 35.0$55.0 \mathrm{~g} / \mathrm{Lb}$. Further, the total plasma globulin (GLUB) level is 25.0-40.0 g/Lb [62].

Renal dysfunction can be fatal for diabetic patients [63]. Hyperuricemia and hyperglycemia are the main causes of renal failure [63]. Diabetic nephropathy, high blood pressure, and high blood sugar are the main causes of renal failure. Kidney function in the kidney disease is an indicator of the activity, vitality, and overall health of kidney. The obtained results refer to the creatinine levels of all treated groups falling in the range of safe creatinine levels that is one of the most important kidney function tests and the results of this parameter are used to evaluate kidney functions [64].

Insulin is an anabolic hormone that promotes glucose uptake, glycogenesis, lipogenesis, and protein synthesis of skeletal muscle and fat tissue through the tyrosine kinase receptor pathway. In addition, insulin is the most important factor in the regulation of plasma glucose homeostasis, as it counteracts glucagon and other catabolic hormones epinephrine, glucocorticoid, and growth hormone. The obtained results are closely similar to Graham et al. [65] who indicated that the insulin range in blood plasma falls between 3 and $19 \mathrm{uIU} / \mathrm{ml}$. Finally, based on previous studies, the role of probiotics in the development of T1D demonstrated that oral probiotics inhibit the development of T1D in diabetic mice model. Therefore, probiotics showed the ability to the intervention of diabetes [15].

\section{Conclusions}

Lactobacillus brevis KLDS 1.0727 and KLDS 1.0373 strains were exhibited to be extremely viable in in vitro experiments and exhibited survival in in vitro digestion models mimicking the gastrointestinal conditions. Moreover, it shows significant hostility against foodborne pathogenic bacteria. In addition, KLDS 1.0727 and KLDS 1.0373 strains expressed adequate GABA that demonstrate a superb physiological effect in in vivo experiment. On the other hand, it shows a significant effect in lowering blood glucose levels or insulin in plasma. In addition, most functional liver and kidney tests fall within the reference range of plasma blood parameters. Therefore, we recommended using Lactobacillus brevis KLDS 1.0727 and KLDS 1.0373 strains widely in the market as a natural source of GABA in pharmaceutical and food applications to reduce the threat of type 1 diabetes.

\section{Data Availability}

The data used to support the findings of this study are available from the corresponding author upon request.

\section{Conflicts of Interest}

The authors declare that there are no conflicts of interest regarding the publication of this paper.

\section{Acknowledgments}

The authors would like to thank Dr. Hamdi Ahmad (mr.ahmadhamdi@yahoo.com) from the University of Edinburgh, UK, for revising the manuscript. This research was funded by National Key Research and Development Program of China under Grant no. 2017YED0400304.

\section{References}

[1] E. Salvetti and P. W. O'Toole, "When regulation challenges innovation: The case of the genus Lactobacillus," Trends in Food Science \& Technology, vol. 66, pp. 187-194, 2017.

[2] A. Abdelazez, Z. Muhammad, and Q. X. Zhang, "Production of a Functional Frozen Yogurt Fortified with Bifidobacterium spp," BioMed Research International, vol. 2017, Article ID 6438528, 10 pages, 2017.

[3] K. Ji, N. Y. Jang, and Y. T. Kim, "Isolation of lactic acid bacteria showing antioxidative and probiotic activities from kimchi and infant feces," Journal of Microbiology and Biotechnology, vol. 25, no. 9, pp. 1568-1577, 2015.

[4] J. Xing, G. Wang, Q. Zhang et al., "Determining Antioxidant Activities of Lactobacilli Cell-Free Supernatants by Cellular Antioxidant Assay: A Comparison with Traditional Methods," PLoS ONE, vol. 10, no. 3, p. e0119058, 2015.

[5] T. Kuda, M. Kawahara, M. Nemoto, H. Takahashi, and B. Kimura, "In vitro antioxidant and anti-inflammation properties of lactic acid bacteria isolated from fish intestines and fermented fish from the Sanriku Satoumi region in Japan," Food Research International, vol. 64, pp. 248-255, 2014.

[6] S. I. Pavlova, A. O. Kilic, S. S. Kilic et al., "Genetic diversity of vaginal lactobacilli from women in different countries based on 16 S rRNA gene sequences," Journal of Applied Microbiology, vol. 92, no. 3, pp. 451-459, 2002.

[7] P. Falck, S. Precha-Atsawanan, C. Grey et al., "Xylooligosaccharides from hardwood and cereal xylans produced by a thermostable xylanase as carbon sources for lactobacillus brevis and bifidobacterium adolescentis," Journal of Agricultural and Food Chemistry, vol. 61, no. 30, pp. 7333-7340, 2013.

[8] Y. Ma, Y. Deng, Z. Xu et al., "Development of a propidium monoazide-polymerase chain reaction assay for detection of viable Lactobacillus brevis in beer," Brazilian Journal of Microbiology, vol. 48, no. 4, pp. 740-746, 2017.

[9] Q. Wu and N. P. Shah, "High gamma-aminobutyric acid production from lactic acid bacteria: Emphasis on Lactobacillus brevis as a functional dairy starter," Critical Reviews in Food Science and Nutrition, vol. 57, no. 17, pp. 3661-3672, 2017.

[10] D. N. D. Riccia, F. Bizzini, M. G. Perilli et al., "Antiinflammatory effects of Lactobacillus brevis (CD2) on periodontal disease," Oral Diseases, vol. 13, no. 4, pp. 376-385, 2007.

[11] A. A. Rushdy and E. Z. Gomaa, "Antimicrobial compounds produced by probiotic Lactobacillus brevis isolated from dairy products," Annals of Microbiology, vol. 63, no. 1, pp. 81-90, 2013.

[12] Y. Ueno, K. Hayakawa, and S. Takahashi, "Purification and characterization of glutamate decarboxylase from Lactobacillus brevis IFO 12005," Biosci Biotechnol Biochem, vol. 61, no. 7, pp. 1168-71, Jul 1997.

[13] H. Zhang, H.-Y. Yao, F. Chen, and X. Wang, "Purification and characterization of glutamate decarboxylase from rice germ," Food Chemistry, vol. 101, no. 4, pp. 1670-1676, 2007. 
[14] J. S. Skyler, G. L. Bakris, E. Bonifacio et al., "Differentiation of diabetes by pathophysiology, natural history, and prognosis," Diabetes, vol. 66, no. 2, pp. 241-255, 2017.

[15] M. A. Atkinson, G. S. Eisenbarth, and A. W. Michels, "Type 1 diabetes," The Lancet, vol. 383, no. 9911, pp. 69-82, 2014.

[16] E. Fan, J. Huang, S. Hu, L. Mei, and K. Yu, "Cloning, sequencing and expression of a glutamate decarboxylase gene from the GABA-producing strain Lactobacillus brevis CGMCC 1306," Annals of Microbiology, vol. 62, no. 2, pp. 689-698, 2012.

[17] E. Boonstra, R. de Kleijn, L. S. Colzato, A. Alkemade, B. U. Forstmann, and S. Nieuwenhuis, "Neurotransmitters as food supplements: the effects of GABA on brain and behavior," Frontiers in Psychology, vol. 6, 2015.

[18] M. Diana, J. Quílez, and M. Rafecas, "Gamma-aminobutyric acid as a bioactive compound in foods: A review," Journal of Functional Foods, vol. 10, pp. 407-420, 2014.

[19] Q. Wu, H. M. Tun, Y.-S. Law, E. Khafipour, and N. P. Shah, "Common distribution of gad operon in Lactobacillus brevis and its GadA contributes to efficient GABA synthesis toward cytosolic near-neutral pH," Frontiers in Microbiology, vol. 8, 2017.

[20] D. Dupont, M. Alric, S. Blanquet-Diot et al., "Can dynamic in vitro digestion systems mimic the physiological reality?" Critical Reviews in Food Science and Nutrition, pp. 1-17, 2018.

[21] P. Chen, Q. Zhang, H. Dang et al., "Screening for potential new probiotic based on probiotic properties and $\alpha$-glucosidase inhibitory activity," Food Control, vol. 35, no. 1, pp. 65-72, 2014.

[22] Y. Bao, Y. Zhang, Y. Zhang et al., "Screening of potential probiotic properties of Lactobacillus fermentum isolated from traditional dairy products," Food Control, vol. 21, no. 5, pp. 695701, 2010.

[23] M. C. Casado Muñoz, N. Benomar, L. L. Lerma, A. Gálvez, and H. Abriouel, "Antibiotic resistance of Lactobacillus pentosus and Leuconostoc pseudomesenteroides isolated from naturallyfermented Alorena table olives throughout fermentation process," International Journal of Food Microbiology, vol. 172, pp. 110-118, 2014.

[24] E. F. S. A. S. Committee, "Guidance on selected default values to be used by the EFSA Scientific Committee, Scientific Panels and Units in the absence of actual measured data," EFSA Journal, vol. 10, no. 3, 2012.

[25] W. P. Charteris, P. M. Kelly, L. Morelli, and J. K. Collins, "Development and application of an in vitro methodology to determine the transit tolerance of potentially probiotic Lactobacillus and Bifidobacterium species in the upper human gastrointestinal tract," Journal of Applied Microbiology, vol. 84, no. 5, pp. 759-768, 1998.

[26] Q. S. Damaceno, J. P. Souza, J. R. Nicoli et al., "Evaluation of Potential Probiotics Isolated from Human Milk and Colostrum," Probiotics and Antimicrobial Proteins, vol. 9, no. 4, pp. 371-379, 2017.

[27] A. M. O. Leite, M. A. L. Miguel, R. S. Peixoto et al., "Probiotic potential of selected lactic acid bacteria strains isolated from Brazilian kefir grains," Journal of Dairy Science, vol. 98, no. 6, pp. 3622-3632, 2015.

[28] C.-H. Wu, S.-M. Huang, and J.-A. Lin, "Inhibition of advanced glycation endproduct formation by foodstuffs," Food \& function, vol. 2, no. 5, pp. 224-234, 2011.

[29] R. S. Surwit, C. M. Kuhn, C. Cochrane, J. A. McCubbin, and M. N. Feinglos, "Diet-induced type II diabetes in C57BL/6J mice," Diabetes, vol. 37, no. 9, pp. 1163-1167, 1988.
[30] L. Chen, D. J. Magliano, and P. Z. Zimmet, "The worldwide epidemiology of type 2 diabetes mellitus-present and future perspectives," Nature Reviews Endocrinology, vol. 8, no. 4, pp. 228-236, 2012.

[31] N. Waki, M. Matsumoto, Y. Fukui, and H. Suganuma, "Effects of probiotic Lactobacillus brevis KB290 on incidence of influenza infection among schoolchildren: an open-label pilot study," Letters in Applied Microbiology, vol. 59, no. 6, pp. 565-571, 2014.

[32] K. Hiraga, Y. Ueno, and K. Oda, "Glutamate decarboxylase from Lactobacillus brevis: Activation by ammonium sulfate," Bioscience, Biotechnology, and Biochemistry, vol. 72, no. 5, pp. 1299-1306, 2008.

[33] A. Sharma and S. Srivastava, "Anti-Candida activity of twopeptide bacteriocins, plantaricins (Pln E/F and J/K) and their mode of action," Fungal Biology, vol. 118, no. 2, pp. 264-275, 2014.

[34] L. Solieri, A. Bianchi, G. Mottolese, F. Lemmetti, and P. Giudici, "Tailoring the probiotic potential of non-starter Lactobacillus strains from ripened Parmigiano Reggiano cheese by in vitro screening and principal component analysis," Food Microbiology, vol. 38, pp. 240-249, 2014.

[35] S. Tulumoglu, Z. N. Yuksekdag, Y. Beyatli, O. Simsek, B. Cinar, and E. Yaşar, "Probiotic properties of lactobacilli species isolated from children's feces," Anaerobe, vol. 24, pp. 36-42, 2013.

[36] W. L. G. de Almeida Júnior, Í. D. S. Ferrari, J. V. de Souza et al., "Characterization and evaluation of lactic acid bacteria isolated from goat milk," Food Control, vol. 53, pp. 96-103, 2015.

[37] C.-F. Guo, S. Zhang, Y.-H. Yuan et al., "Comparison of lactobacilli isolated from Chinese suan-tsai and koumiss for their probiotic and functional properties," Journal of Functional Foods, vol. 12, pp. 294-302, 2015.

[38] R. Sahadeva, S. Leong, and K. Chua, "Survival of commercial probiotic strains to $\mathrm{pH}$ and bile," International Food Research Journal, vol. 18, no. 4, 2011.

[39] Q. Liao, X. Hang, X. Liu et al., "The influence of $\mathrm{pH}$ on heat stress response by probiotic Lactobacillus plantarum LP-Onlly," Annals of microbiology, vol. 60, no. 2, pp. 341-348, 2010.

[40] Y. Zhang and W. Yew, "Mechanisms of drug resistance in Mycobacterium tuberculosis [State of the art series. Drugresistant tuberculosis. Edited by CY. Chiang. Number 1 in the series]," The International Journal of Tuberculosis and Lung Disease, vol. 13, no. 11, pp. 1320-1330, 2009.

[41] G. Vinderola, B. Capellini, F. Villarreal et al., "Usefulness of a set of simple in vitro tests for the screening and identification of probiotic candidate strains for dairy use," LWT-Food Science and Technology, vol. 41, no. 9, pp. 1678-1688, 2008.

[42] C. L. Ramos, L. Thorsen, R. F. Schwan, and L. Jespersen, "Strainspecific probiotics properties of Lactobacillus fermentum, Lactobacillus plantarum and Lactobacillus brevis isolates from Brazilian food products," Food Microbiology, vol. 36, no. 1, pp. 22-29, 2013.

[43] M. Hyacinta, K. S. Hana, B. Andrea et al., "Bile tolerance and its effect on antibiotic susceptibility of probiotic Lactobacillus candidates," Folia Microbiol (Praha), vol. 60, no. 3, pp. 253-257, 2015.

[44] I. Klare, C. Konstabel, G. Werner et al., "Antimicrobial susceptibilities of Lactobacillus, Pediococcus and Lactococcus human isolates and cultures intended for probiotic or nutritional use," Journal of Antimicrobial Chemotherapy, vol. 59, no. 5, pp. 900 912, 2007.

[45] Q. Wu and N. P. Shah, "Restoration of GABA production machinery in Lactobacillus brevis by accessible carbohydrates, 
anaerobiosis and early acidification," Food Microbiology, vol. 69, pp. 151-158, 2018.

[46] L. Zhang, Evaluation of the Potential Probiotic Properties and Immune Regulation Function of Lactobacillus Strains Isolated from Traditional Fermented Yak Milk, Ph. D. Thesis, Gansu Agricultural University, Lanzhou, Gansu, China, 2011.

[47] P. Asurmendi, M. García, L. Pascual et al., "Biocontrol of Listeria monocytogenes by lactic acid bacteria isolated from brewer's grains used as feedstuff in Argentina," Journal of Stored Products Research, vol. 61, pp. 27-31, 2015.

[48] N. Gautam and N. Sharma, "Evaluation of probiotic potential of new bacterial strain, Lactobacillus spicheri G2 isolated from Gundruk," Proceedings of the National Academy of Sciences, India Section B: Biological Sciences, vol. 85, no. 4, pp. 979-986, 2015.

[49] B. T. Fossi, N. B. Ekue, G. T. Nchanji et al., "Probiotic properties of lactic acid bacteria isolated from fermented sap of palm tree (Elaeis guineensis)," Journal of Microbiology and Antimicrobials, vol. 7, no. 5, pp. 42-52, 2015.

[50] M. J. Scourboutakos, B. Franco-Arellano, S. A. Murphy et al., "Mismatch between Probiotic Benefits in Trials versus Food Products," Nutrients, vol. 9, no. 4, 2017.

[51] A. Belicová, M. Mikulášová, and R. Dušinský, "Probiotic potential and safety properties of lactobacillus plantarum from Slovak Bryndza cheese," BioMed Research International, vol. 2013, 8 pages, 2013.

[52] M. A. Ehrmann, P. Kurzak, J. Bauer, and R. F. Vogel, "Characterization of lactobacilli towards their use as probiotic adjuncts in poultry," Journal of Applied Microbiology, vol. 92, no. 5, pp. 966-975, 2002.

[53] T. García-Cayuela, A. M. Korany, I. Bustos et al., "Adhesion abilities of dairy Lactobacillus plantarum strains showing an aggregation phenotype," Food Research International, vol. 57, pp. 44-50, 2014.

[54] H. Cheng and R. C Harris, "Renal endothelial dysfunction in diabetic nephropathy," Cardiovascular \& Haematological Disorders-Drug Targets (Formerly Current Drug TargetsCardiovascular \& Hematological Disorders), vol. 14, no. 1, pp. 22-33, 2014.

[55] S. Lenzen, "The mechanisms of alloxan-and streptozotocininduced diabetes," Diabetologia, vol. 51, no. 2, pp. 216-226, 2008.

[56] D. H. Wasserman, "Four grams of glucose," American Journal of Physiology-Endocrinology and Metabolism, vol. 296, no. 1, pp. E11-E21, 2009.

[57] D. B. Sacks, M. Arnold, G. L. Bakris et al., "Guidelines and recommendations for laboratory analysis in the diagnosis and management of diabetes mellitus," Diabetes Care, vol. 34, no. 6, pp. e61-e99, 2011.

[58] A. D. Association, Diabetes and retinopathy (eye complications), vol. 19, 2009.

[59] D. Lloyd-Jones, R. J. Adams, T. M. Brown et al., "Heart disease and stroke statistics-2010 update," Circulation, vol. 121, no. 7, pp. e46-e215, 2010.

[60] S. Agrahari and K. Gopal, Retracted: Fluctuations of certain biochemical constituents and markers enzymes as a consequence of monocrotophos toxicity in the edible freshwater fish, channa punctatus, Elsevier, 2009.

[61] A. Prakasam, S. Sethupathy, and K. V. Pugalendi, "Influence of Casearia esculenta root extract on protein metabolism and marker enzymes in streptozotocin-induced diabetic rats," Polish Journal of Pharmacology, vol. 56, no. 5, pp. 587-593, 2004.
[62] P. N. Newsome, R. Cramb, S. M. Davison et al., "Guidelines on the management of abnormal liver blood tests," Gut, vol. 67, no. 1, pp. 6-19, 2018.

[63] M. Brownlee, "The pathobiology of diabetic complications: a unifying mechanism," Diabetes, vol. 54, no. 6, pp. 1615-1625, 2005.

[64] P. E. Stevens and A. Levin, "Evaluation and management of chronic kidney disease: synopsis of the kidney disease: improving global outcomes 2012 clinical practice guideline," Annals of Internal Medicine, vol. 158, no. 11, pp. 825-830, 2013.

[65] T. E. Graham, C. J. Wason, M. Blüher, and B. B. Kahn, "Shortcomings in methodology complicate measurements of serum retinol binding protein (RBP4) in insulin-resistant human subjects," Diabetologia, vol. 50, no. 4, pp. 814-823, 2007. 


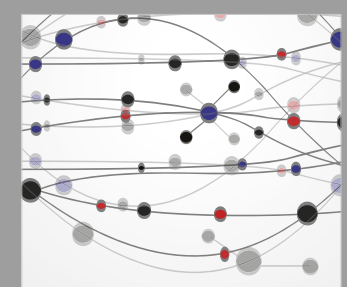

The Scientific World Journal
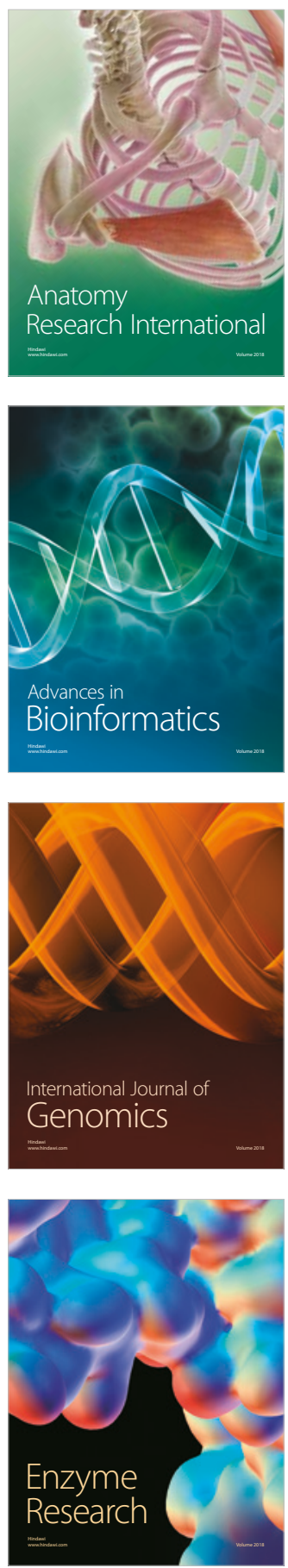
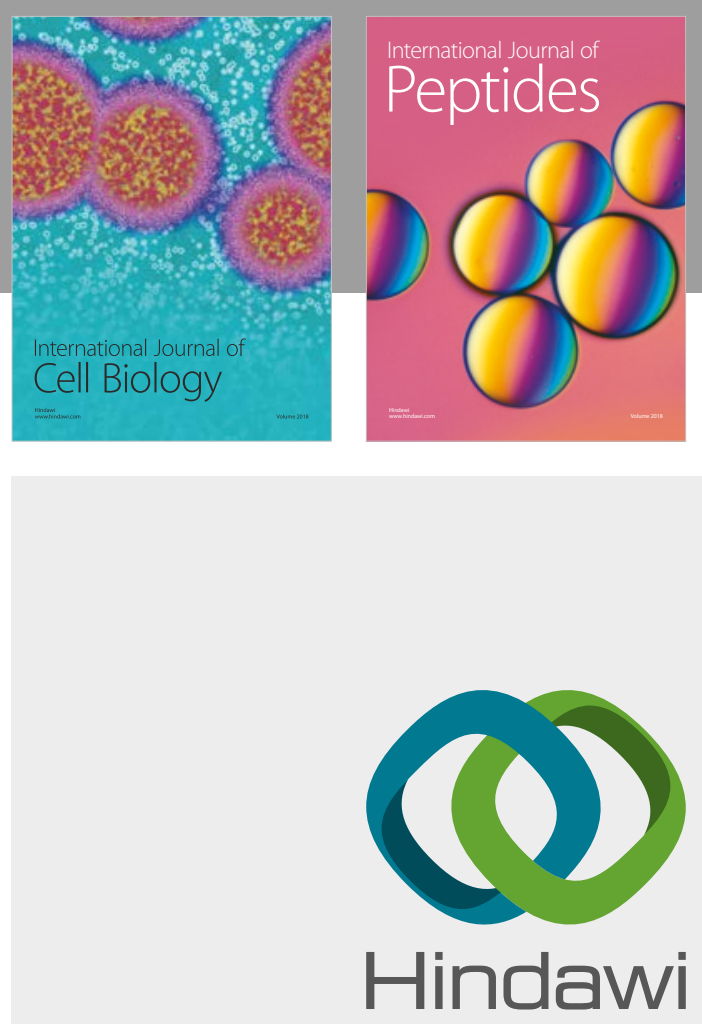

Submit your manuscripts at

www.hindawi.com
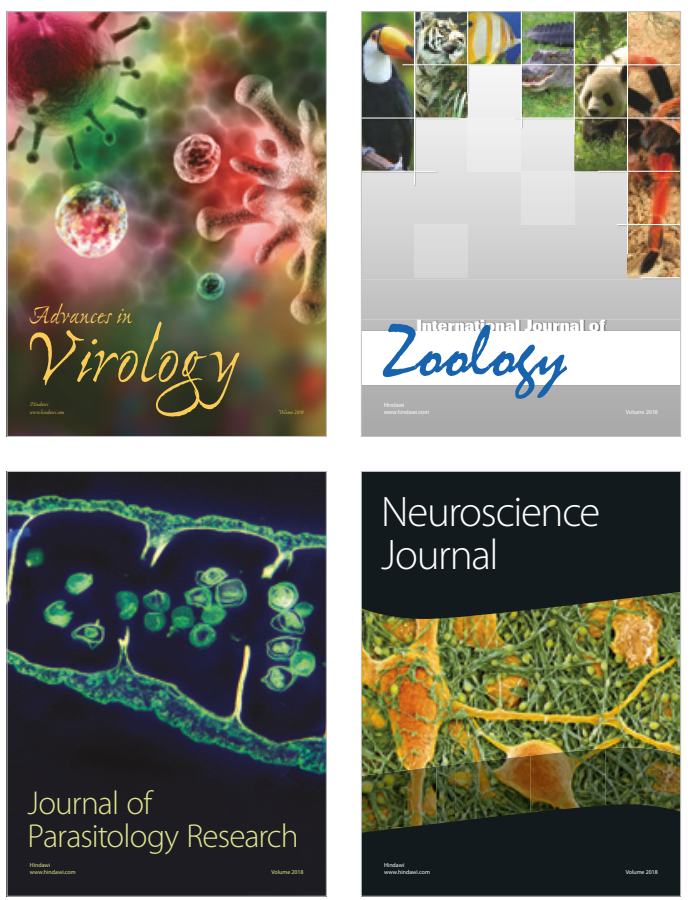
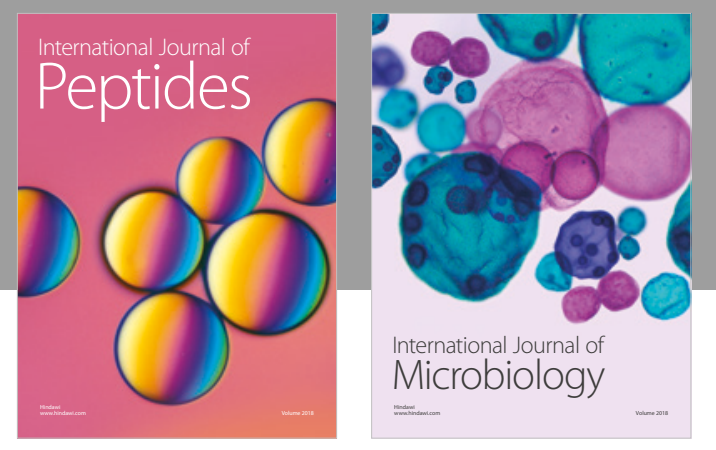

nternational Journal of Microbiology
Journal of
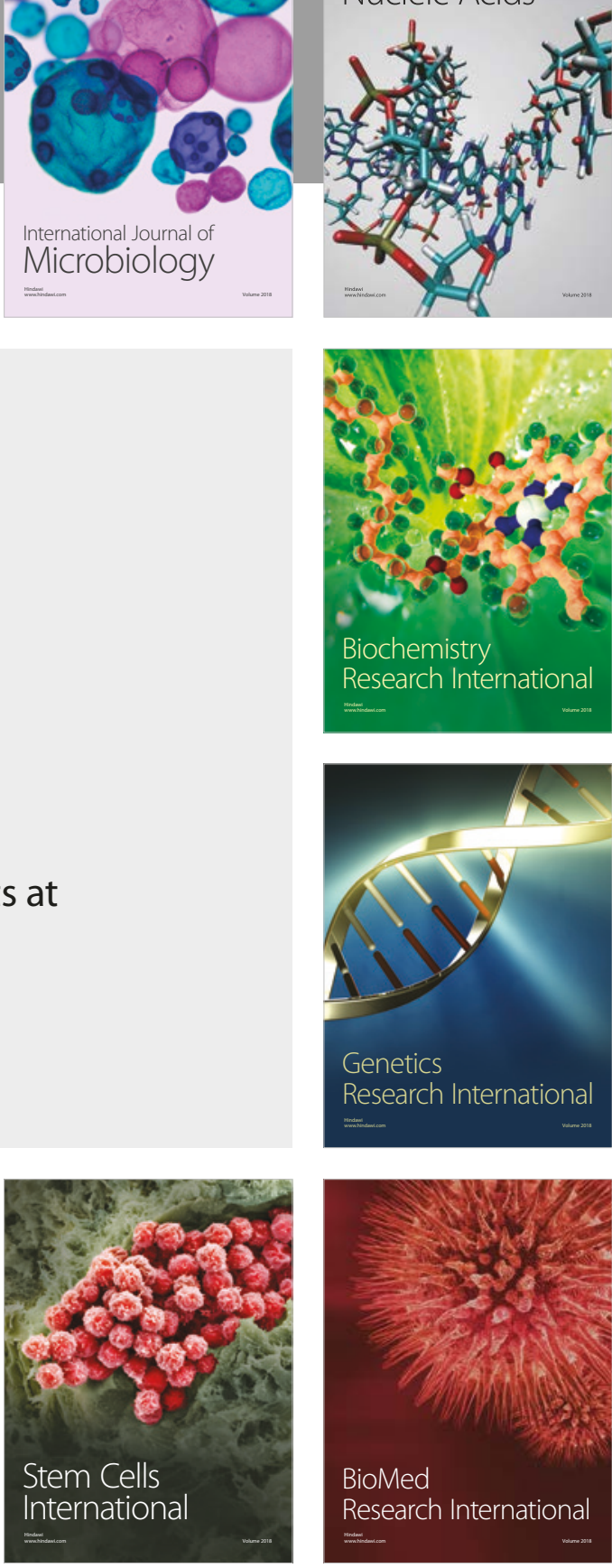
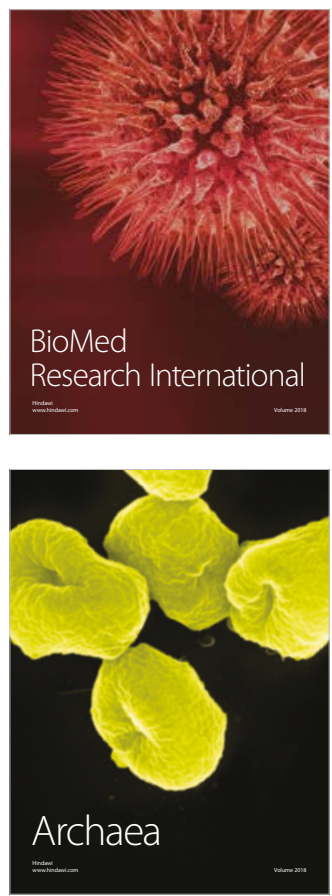